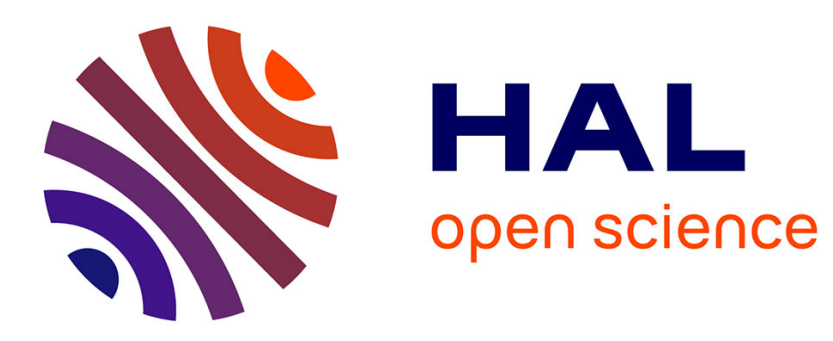

\title{
Energy consumption and activity patterns: an analysis extended to total time and energy use for French households
}

Simona de Lauretis, Frédéric Ghersi, Jean-Michel Cayla

\section{- To cite this version:}

Simona de Lauretis, Frédéric Ghersi, Jean-Michel Cayla. Energy consumption and activity patterns: an analysis extended to total time and energy use for French households. Applied Energy, 2017, 206, pp.634-648. 10.1016/j.apenergy.2017.08.180 . hal-01682301

\section{HAL Id: hal-01682301 https://hal.science/hal-01682301}

Submitted on 25 May 2018

HAL is a multi-disciplinary open access archive for the deposit and dissemination of scientific research documents, whether they are published or not. The documents may come from teaching and research institutions in France or abroad, or from public or private research centers.
L'archive ouverte pluridisciplinaire HAL, est destinée au dépôt et à la diffusion de documents scientifiques de niveau recherche, publiés ou non, émanant des établissements d'enseignement et de recherche français ou étrangers, des laboratoires publics ou privés. 


\title{
Energy consumption and activity patterns: an analysis extended to total time and energy use for French households
}

\author{
Simona De Lauretis ${ }^{* a, b}$, Frédéric Ghersi ${ }^{a}$, and Jean-Michel Cayla ${ }^{b}$ \\ ${ }^{a}$ Centre International de Recherche sur l'Environnement et le Développement (CIRED), \\ AgroParisTech, CIRAD, CNRS, EHESS, Ecole des Ponts ParisTech, Université Paris-Saclay, 94130 \\ Nogent-sur-Marne, France \\ ${ }^{\mathrm{b}}$ Electricité de France (EDF RधD), site des Renardières, 77818 Moret sur Loing CEDEX, France
}

Keywords: time use, household consumption, energy consumption, household heterogeneity

\begin{abstract}
Household lifestyles, and activity patterns in particular, greatly influence household energy use. In this paper we analyse the disparities in current activity patterns and related energy consumptions and expenditures of households, for a comprehensive set of everyday activities covering 24 hours. Thanks to detailed data on energy consumption by end use, we are able to allocate the total of household energy consumptions to the appropriate activities. We comment on average energy and expenditure intensities of time uses of the total population as well as of income, household-composition and housing-type subgroups. Income, an obvious driver of energy and expenditure intensities, is revealed to influence time use as well. Household composition and housing type are also associated with substantial variations in activity patterns and in the energy and expenditure intensities of activities, even within a given income group. Indeed, sometimes the variations associated with income are smaller than the variations associated with other variables. We therefore underline the importance of household disaggregation in household energy analyses, to properly account for such disparities.
\end{abstract}

Link to published article : https://doi.org/10.1016/j.apenergy.2017.08.180

\footnotetext{
${ }^{*}$ Corresponding author. E-mail address: delauretis@centre-cired.fr; tel. +33 160736665. Postal address: CIRED, Campus du Jardin Tropical, 45 bis Avenue de la Belle Gabrielle, 94736 Nogent-sur-Marne Cedex, France
} 


\section{Introduction}

Household consumption is a key driver of energy demand and of greenhouse gas emissions: in addition to direct household energy use, it has a bearing on the energy consumption of economic sectors embodied in consumed goods and services. For this reason, the implications of consumer lifestyle on energy use and emissions have attracted a growing interest in recent years (see e.g. $[1,2,3])$. Furthermore, changes in consumption patterns are increasingly regarded as necessary to meet emissions reduction objectives beyond the reach of energy efficiency improvements $[4,5,6]$.

Beyond the microeconomic standard of utility maximisation under budget constraint, consumption choices do not derive solely from monetary considerations: an extensive literature stresses the importance of emotional, habitual and social aspects, in particular concerning energy use $[7,8,9]$. One other fundamental constraint on consumption patterns is time. Time is a budget irrevocably set for all individuals alike. Any increase of the time spent on one activity must be compensated by a decrease of the time allocated to other activities. Indeed, the availability of time could constrain future consumption choices more than the availability of monetary resources. Since Becker introduced the household production approach [10], several studies have considered the implications of the substitution of goods for time and of the relative expenditure intensities of different activities [11, 12].

For these reasons, as Schipper et al. [13] first pointed out, a fitting way to analyse the impact of lifestyles on energy use is to focus on the interdependencies of time use and energy consumption. Only a few empirical studies besides Schipper et al. [13] adopt this approach, crossing budget and time-use data to compare the energy consumptions associated with different everyday activities. Jalas [14] analyses the energy intensity of time spent on several activities for 2-person Finnish households in 1990, to reveal that the highest intensity is associated with car travel, followed by eating out and clothes washing or ironing. For the author, a comparison of energy intensities is useful to shed light on the possibility of a rebound effect with respect to time, if households externalise some services (e.g. clothes washing) and replace them with activities that are more energy-intensive than the externalised service itself. Brenčič and Young [15] also consider the implications of a rebound effect with respect to time, by studying the impact of time-saving appliances (like microwaves and dishwashers) on time use patterns and energy consumption. They find some evidence of rebound effect with respect to time, as households who own a dishwasher tend to use washing machines and clothes dryers more often than households who do not. Jalas [16] further considers the change in activity patterns and energy intensities of Finnish households between 1990 and 2000, showing that the energy intensities of activities increase over the period, but activity patterns shift in favour of less energy-intensive activities. This decomposition analysis is extended to 2009 by Jalas and Juntunen [17], who show that during the 2000s the energy intensities continued to rise, and activity patterns shifted again towards more energy-intensive activities. Besides, the authors observe significant differences in energy intensities across different household compositions, highlighting the need to take household composition into account (although some of the variation they observe can be attributed to income effects). Similarly, Druckman et al. [18] study the greenhouse-gas emissions associated with everyday activities of British households and the GHG intensities of time spent in these activities. They find that personal care activities (including clothes washing and medical care) have the highest GHG intensity, followed by meals (at home or away from home) and commuting. The large differences in the energy intensity of activities reported by this literature draw attention to the significance of the impact that changes in lifestyles, which imply changes in activity patterns, can have on both direct and indirect (embodied in non-energy 
expenses) energy consumption.

Besides the studies cited above, which focus on the implications of lifestyles and energy intensities of activities for household energy use, it is worth noting that time use information has other important applications in energy research. For example, the energy intensity of activities, as regards electricity, is relevant for load profiling and demand management [19, 20].

The purpose of our work is twofold: to quantify the variability of direct energy intensity and non-energy expenditure intensity of daily activities and to investigate to what extent activity patterns and the energy- and non-energy intensities of activities are sensitive to household characteristics. For the latter purpose we explore 3 axes of household differentiation: income, household composition and housing type. Our analyses rest on the combination of a number of datasets to construct a comprehensive, consistent vision of time use and associated energy consumptions and non-energy expenses. This allows us reaching further than previous studies in two respects. The first is that our results extend to all activities, covering all 24 hours of an "average" day, whereas the studies previously cited exclude some activities for the inability to properly allocate expenditure and energy or emissions data. The second is that detailed data on energy consumption by end use (taking into consideration the heterogeneity of energy prices, household equipment and behaviour) allows us to cover the totality of household direct energy consumption, attributing it to the appropriate activities.

In section 2 of this paper we present our methodology. In section 3 we comment on the resulting activity patterns, energy intensities and non-energy expenditure intensities of time uses for the average household and for household subgroups defined by income, demographic composition and type of dwelling. In section 4 we discuss our results and conclude.

\section{Methodology}

Because of the unavailability of any recent survey simultaneously reporting time-use and expenditure data, our study primarily builds on the statistical treatment and analysis of two data sets: the French 2009-2010 time-use survey (Emploi du temps, EDT) [21] and the French 2011 household expenditure survey (Budget De Famille, BDF) [22], both carried out by the French statistics agency INSEE.

The time-use EDT survey consists of 27903 time diaries of individuals above 11. Each time diary reports activities at 10-minute intervals for a 24-hour period, as well as their locations. Time diaries were collected in 6 survey waves covering one full year, to warrant seasonal representativity. The household expenditure BDF survey provides data about income sources and expenditures of 15797 households. Expenditure diaries cover a period of one week for daily expenses, but extend to the full year leading up to the survey period for non-daily expenses like energy. Similarly to EDT, they are the result of 6 survey waves spanning over one year and are therefore representative of the whole year. INSEE provides weights to scale up the observations of both EDT and BDF at the level of the entire French population. Our analyses systematically concern such scaled-up data.

To cross EDT and BDF data we could theoretically estimate either time uses of BDF households based on EDT, or expenditures of EDT individuals based on BDF. We settle on the former option because BDF does not provide the fully individualised expenses that would be required to assign consumption budgets to EDT individuals, ${ }^{1}$ whereas it describes the composition of each household, giving detailed information about household members. We can therefore es-

\footnotetext{
${ }^{1}$ Because of this understandable limitation of BDF, our analysis systematically operates on household data, which we convert into individual data using the comprehensive BDF data on each of its households' composition.
} 
timate the time uses of all individuals of each household in BDF and sum them up to obtain household time uses.

The objective of our study then calls for an allocation of expenditures, and especially energy expenditures, to time uses, and a conversion of energy expenditures into physical units. We also decide to treat transport similarly to energy, i.e. as ancillary to (out-of-home) activities, which requires disaggregation of transport time, expenses and direct energy consumptions by purpose. To perform these further data treatment steps we exploit 4 additional surveys on residential energy consumption and travel behaviour via clustering, i.e. assuming that the average conditions (expense and time breakdowns, energy prices) observed on specific household subgroups of the 4 additional surveys apply to all members of corresponding subgroups of our core BDF survey.

We summarise the steps of our database building in Figure 1. The following subsections successively detail each step.

\subsection{Choice of time-use categories and time-use estimation}

The first step of our data treatment consists in estimating activity patterns for individuals of the BDF survey. There are 140 time-use categories in the EDT survey. We initially group these categories in 15 everyday activities (Table 1), although we will eventually distribute two of these time uses, namely the transport-time categories, to away-from-home activities. Our classification is a compromise between the detail of daily undertakings and both the ease of allocation of expenditure to the activities and the quality of the statistical estimation of time uses. It is similar to that of previous studies $[17,18,11]$. We split some activities in two based on whether they take place at home or away from home and, for home-based activities, on whether they require specific energy consumption or not. For example, we split leisure at home in two separate sets: an "energy-intensive" leisure that requires some kind of electric/electronic device (e.g. watching TV, surfing the Internet, playing video games) and a "non-energy-intensive" leisure, which includes conversations and reading. Our activities eventually group all 140 EDT time-use categories, therefore covering the entire 24-hour period described in each time-use diary. $^{2}$

We use weighted least squares regressions ${ }^{3}$ to estimate each time use across all individuals of EDT. Because the estimation is meant to be applied to BDF, we specifically select a set of explanatory variables common to both surveys (see Table 1 in the Appendix for an exhaustive list). These include socio-economic and demographic characteristics (income, age, sex, type of occupation, type of household, nationality, home-ownership status), geographical variables (size of urban area, type of urban area, type of neighbourhood, geographical area), housing characteristics (type of dwelling, surface, type of buildings nearby), appliance ownership (TV, computer, Internet equipment, telephone, mobile phone, microwave, dishwasher, washing machine, car, scooter/motorcycle), possession of pets, employment of a domestic worker, type of day (working day, half-day, holiday, sick leave, other). ${ }^{4}$ The "type of day" variable, associated

\footnotetext{
${ }^{2}$ The detailed allocation of EDT time-use categories to aggregate activities is available from the authors upon request.

${ }^{3}$ There are several examples of statistical matching of time use and household expenditure surveys using regressions (e.g. [23], [24]). Others use a score-matching approach [12], which has the advantage of preserving the variance of generated values with respect to starting values. For our analysis of various household group averages this advantage is irrelevant.

${ }^{4}$ We treated the only serious issue of collinearity between variables, i.e. that between age and occupation (one of the occupations being retirement), by producing a principal component analysis (PCA) of the two variables (details available from the authors upon request).
} 


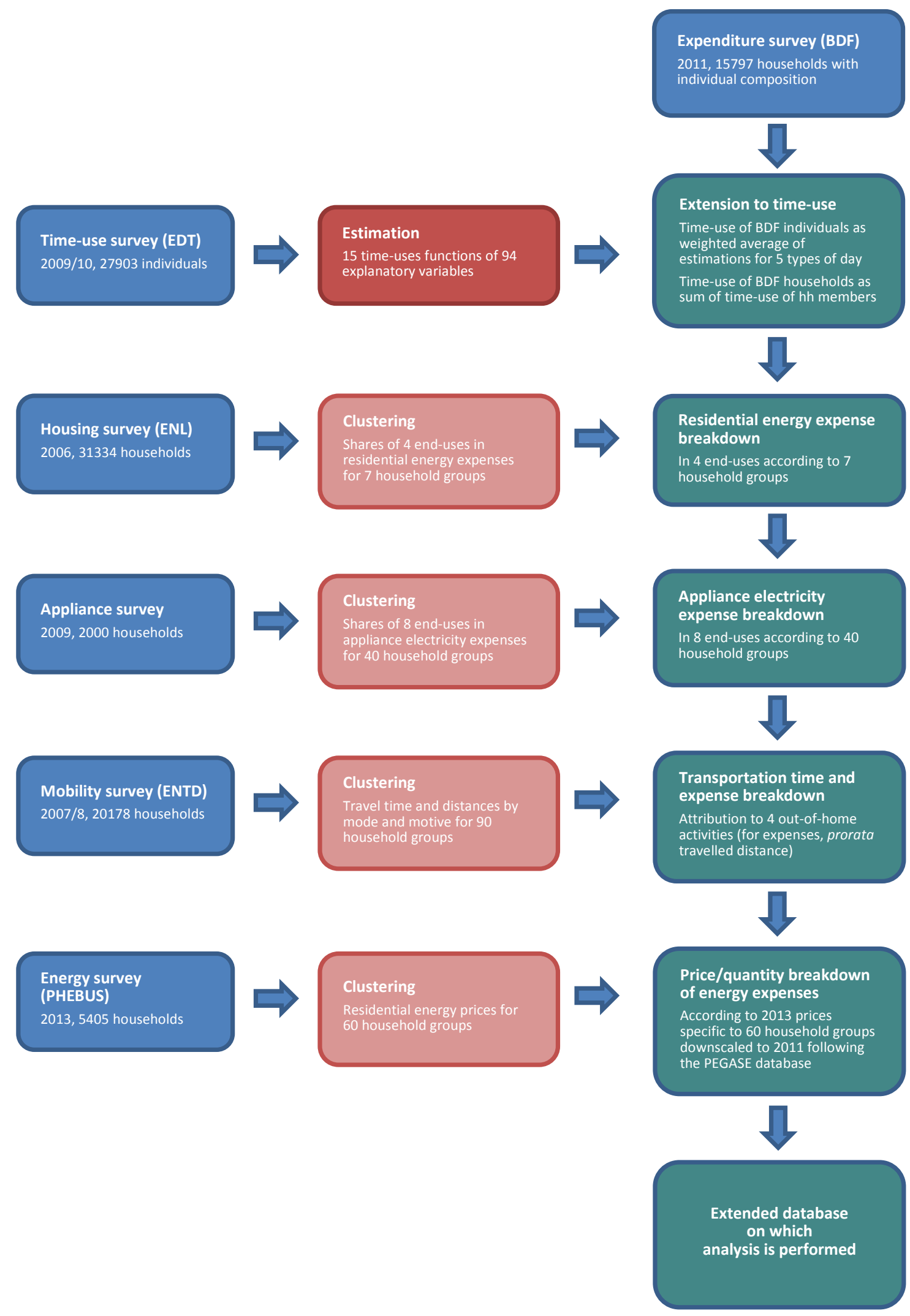

Figure 1: Database building steps 
Table 1: Allocation of time uses to activities

\begin{tabular}{ll}
\hline \hline Activity & Time-use categories \\
\hline Care & Caring for another member of the household (children or adults) or \\
& caring for pets \\
Eating at home & Meal time at home (excluding meal preparation and cleaning up) \\
Eating out & Meal time away from home (excluding meals at work) \\
Housework: meals & Meal preparation and clean-up \\
Housework: home & House cleaning or tidying up, maintenance, gardening, do-it-yourself \\
Housework: clothes & Laundry and clothes care \\
Leisure (energy-intensive) & Television, computer, Internet, video games, telephone conversations, \\
& listening to music/radio, watching/making videos \\
Leisure (non energy-intensive) & Reading, conversations, crafts, playing music, practising sports at \\
& home \\
Personal time & Personal care, hygiene, beauty care, health care at home \\
Shopping \& administration & Shopping, health care away from home, running errands \\
Sleep & Sleeping, being ill in bed \\
Sport \& outings & Sport away from home, visits, social events, sport events, cultural \\
& events \\
Work \& study & Paid work and study, including meals at work \\
Commuting & Trips from home to work or to educational establishment and return \\
Other travel time & Trips for all other purposes \\
\hline
\end{tabular}

to time diaries in the EDT survey, allows addressing the difference between working days and days not worked, resulting in better estimates in terms of coefficients of determination and normality of the residuals. However, this variable is absent in the BDF household expenditure survey, as expenditure diaries cover a 7-day period and are then extrapolated to annual expenses and completed with annualised non-daily expenses (see above). To reveal corresponding average annual activity patterns, for each BDF individual we estimate time use for each type of day. ${ }^{5}$ Then, we determine annual time uses by applying to each BDF individual the annual distribution of day types specific to their socio-economic group and type of occupation, according to EDT. We derive activity patterns for an "average day of the year" by dividing yearly time uses by 365 days. In the end, the estimated daily time uses sum up to 24 hours for each individual by nature of the method, considering the consistency of EDT data (which systematically sum up to 24 hours as well). Table 2 in the Appendix reports the quality of all our estimations.

\subsection{Matching expenditures and time uses}

The BDF survey provides expenditure data at 5-digit level of $\mathrm{COICOP}^{6}$ classification, for a total of 248 items. We allocate these items to 13 of our 15 time-use activities, excluding the two travel activities, which we reallocate to away-from-home activities to acknowledge their ancillary status (akin to that of energy consumptions). For example, we associate all food expenditures to the "Eating at home" activity, medicines and personal care products to "Personal time", leisure equipment to the corresponding type of leisure activity, etc. We however assume that some expenses, like clothing, clothing accessories, tobacco products, insurance as

\footnotetext{
${ }^{5}$ Because EDT only surveys individuals above 11, we do not estimate time uses for any BDF household member below that age.

${ }^{6}$ Classification Of Individual COnsumption according to Purpose, published by the United Nations Statistics Division.
} 
well as all expenditures related to housing (rents, furniture and equipment, which must be paid for whatever the time share of away-from-home activities) are independent from the allocation of time; we therefore exclude them from the analysis. In addition, we disregard all investments and taxes. The only capital expenditure included in the analysis is expenditure on cars, as sustainable development policies often include a reduction of car use and car ownership. Similar assumptions have been made by Druckman et al. [18] and Jalas and Juntunen [17]. Table 2 provides further detail on our allocation of expenditures.

The allocation of residential energy expenses, travel time and travel expenses requires further exposition, to which we now turn.

Table 2: Allocation of expenditures to activities

\begin{tabular}{|c|c|}
\hline Activity & Expenditure categories \\
\hline Care & $\begin{array}{l}\text { Expenditure related to pets; heating and lighting expenditures pro rata } \\
\text { time use }\end{array}$ \\
\hline Eating at home & $\begin{array}{l}\text { All food expenditure; tableware; heating and lighting expenditures pro } \\
\text { rata time use }\end{array}$ \\
\hline Eating out & Expenditure for meals away from home; specific travel expenditure \\
\hline Housework: clothes & $\begin{array}{l}\text { Cloth, accessories, sewing items; specific electricity consumption; heating } \\
\text { and lighting expenditures pro rata time use }\end{array}$ \\
\hline Housework: home & $\begin{array}{l}\text { Cleaning and maintenance products, expenditure for horticulture, food } \\
\text { for farm animals; heating and lighting expenditures pro rata time use }\end{array}$ \\
\hline Housework: meals & $\begin{array}{l}\text { Kitchen utensils and their maintenance; energy for cooking; heating and } \\
\text { lighting expenditures pro rata time use }\end{array}$ \\
\hline Leisure (energy-intensive) & $\begin{array}{l}\text { TV sets, telephones, radios, computers, telephone and internet subscrip- } \\
\text { tions, cinema and photo equipment; specific electricity consumption; } \\
\text { heating and lighting expenditures pro rata time use }\end{array}$ \\
\hline Leisure (non energy-intensive) & $\begin{array}{l}\text { Postal services, optical instruments, music instruments, non-electronic } \\
\text { leisure equipment; games (except video games), books, newspapers, sta- } \\
\text { tionery; heating and lighting expenditures pro rata time use }\end{array}$ \\
\hline Personal time & $\begin{array}{l}\text { Medicines, healthcare products, plasters, beauty care and hygiene prod- } \\
\text { ucts; warm water consumption; specific electricity consumption; heating } \\
\text { and lighting pro rata time use }\end{array}$ \\
\hline Shopping \& admin. & $\begin{array}{l}\text { Beauty salons, healthcare services away from home; specific travel ex- } \\
\text { penditure }\end{array}$ \\
\hline Sleep & Heating expenditures pro rata time use \\
\hline Sport \& outings & $\begin{array}{l}\text { Sport and open-air leisure equipment, cultural and sports tickets and } \\
\text { subscriptions, gambling; specific travel expenditure }\end{array}$ \\
\hline Work \& study & $\begin{array}{l}\text { Expenditure for education and for meals at the workplace or at school; } \\
\text { specific travel expenditure }\end{array}$ \\
\hline
\end{tabular}

The BDF survey reports 8 types of residential energy expenditures based on the sum of energy invoices over the 12 months preceding the survey period. To attribute a share of each of these expenditures to each home activity we use two additional surveys. First, we use clustering to disaggregate energy expenses across 4 broad end-uses: heating, water heating, cooking and electricity for appliances. We compute the distribution of these 4 end-uses for 7 household groups defined by their main heating system, from the 2006 French housing survey [25]. We similarly separate BDF households in 7 heating-system groups and apply to all members of each group the average end-use shares computed in the housing survey for the corresponding group. We allocate cooking energy expenses to the "Housework: meals" time use and water heating expenses to the "Personal time" activity. ${ }^{7}$ Then we use clustering again to disaggregate

\footnotetext{
${ }^{7}$ Thus neglecting hot water uses for cleaning purposes.
} 
the expenditure associated with appliance electricity consumption across 8 detailed end-uses. ${ }^{8}$ For this, we lean on a 2009 survey carried out by the R\&D department of the EDF electricity company on 2000 households. ${ }^{9}$ We calculate average expenditure shares for the 8 end-uses for 40 household types defined by income quintile, ${ }^{10}$ household composition ${ }^{11}$ and type of housing, ${ }^{12}$ and we apply these shares to the appliance electricity consumption of BDF households based on their household type.

Most resulting expenses are straightforwardly allocated to the various time uses. Heating and cooling expenditures are spread across all home activities pro rata time use ${ }^{13}$ Lighting expenditures are similarly distributed, except to the "Sleep" activity. In the end, energy expenditures for home activities are the sum of a "base" energy expense on heating or air conditioning and lighting, and of energy expenses specific to each activity (energy for cooking, electricity for household appliances or for leisure equipment, etc.).

To complete our matching of expenditures and time uses we allocate travel expenditures, including direct fuel expenditures, to the 4 away-from-home activities, according to the corresponding travel times, purposes and modes. Direct fuel expenditures are the only energy expenditure associated with away-from-home activities, as households do not directly pay for any other energy consumption incurred by such activities (e.g. at work or in public places). As previously hinted, we simultaneously distribute our 2 initial travelling time categories over the same 4 away-from-home activities, thus recognising the ancillary dimension of travel. The EDT survey singles out commuting trips, whose expenses and time we directly link to the "Work \& study" activity. To disaggregate the "other travel time" we turn yet to another survey, the 2007-2008 French travel survey [26], computing average travel times by purpose for household groups defined by income quintile, household composition ${ }^{14}$ and type of residential area. ${ }^{15}$ As BDF does not include any variable describing the type of residential area, we use its city size variable as a proxy: we determine, in the travel survey, the shares of households living in each residential area type for all city sizes; then, we use these shares as weights to compute a weighted average value of mode shares, purpose shares, time shares and distance shares for each combination of income quintile and household composition. Finally, we disaggregate travel times by purpose (that is, by activity) for each household type and each transport mode in proportion to the travel time shares we calculated, and we disaggregate travel expenditure (including fuel) in proportion to the appropriate distance shares.

\subsection{Converting energy expenses into volume energy consumptions}

For each household and each activity, we convert energy expenses into volume energy consumptions based on energy prices specific to each energy form and household type, to account

\footnotetext{
${ }^{8}$ Air conditioning, mechanical ventilation, lighting, kitchen appliances (refrigerators, freezers, dishwashers and other kitchen appliances), washing machines \& clothes dryers, electronic equipment for leisure (TV sets, computers, other ICT equipment), appliances for personal care, gardening \& outdoor appliances.

${ }^{9}$ This survey provides information on the use of 60 household appliances by 2000 households, describing for each appliance: ownership rate, energy label, age, size, frequency of use, time of use and settings.

${ }^{10}$ Here and hereafter, by "income" we more precisely mean gross disposable income per consumption unit.

${ }^{11}$ Single person below 65 , couple without children with person of reference (PR) below 65 , household with children, household with PR above 65.

${ }^{12}$ Houses vs. apartments.

${ }^{13}$ For want of data on averaged thermostat adjustments during specific activities as, typically, "Sleep".

${ }^{14}$ According to the same modalities as those applied in the analyses of BDF and EDT: single person 65 or below, single person above 65 , single parent, couple with children, couple without children with PR 65 or below, couple without children with PR above 65 .

${ }^{15}$ In 3 modalities: urban/central, urban/suburbs, rural.
} 
for the fact that fixed charges vary with the type of contract subscribed. We again differentiate 60 household types based on income quintile, household composition and housing type, and compute average energy prices for each household type from the PHEBUS survey [27], which describes residential energy consumption and expenditure for French households in 2012. We transpose 2012 price data to 2010 by way of the PEGASE database [28], which provides yearly energy price statistics broken down by type of contract for electricity and natural gas.

Concerning transport fuel consumptions, because BDF does not differentiate between petrol and diesel fuel expenditures, we must determine an average price of fuel for each household type, based on their petrol and diesel fuel consumptions in the French 2008 travel survey and on 2010 petrol and diesel fuel prices in France [29].

\subsection{Computing energy and non-energy expenditure intensities of time uses}

The conversion of energy expenses into physical energy consumptions completes the chain of data treatments that produces our extended database (see Figure 1). We can now turn to data analysis by computing the energy and non-energy expenditure (hereafter "non-E") intensities of time uses. Because the time spent on some activities by some households is nil, we cannot compute the intensities of time uses for all households and then average them. Rather, we first determine for each activity the average energy consumptions (in volume) per consumption unit $(\mathrm{CU})^{16}$, non-energy expenditure per $\mathrm{CU}$ and time use per person above 11 -systematically factoring in the representativity weights provided by INSEE. Then, we compute the intensities as ratios of theses averages.

If household $i$, of representativity weight $w_{i}$, counting $n_{i}$ consumption units and $p_{i}$ persons above 11, spends $h_{i}$ hours (per person) and $€_{i}$ euros (per CU) on one activity, and uses $E_{i}$ energy units (per CU) in the process, then we compute the non-E intensity of time spent on this activity as (1) and its energy intensity, accordingly, as (2). Household $i$ belongs to the total database population or to any subsets thereof. We report intensities respectively as $€$ or kWh per hour of activity. ${ }^{17}$

$$
\begin{aligned}
& \text { non-E intensity }=\frac{\sum_{i} w_{i} \epsilon_{i / n_{i}}}{\sum_{i} w_{i}} / \frac{\sum_{i} w_{i} h_{i / p_{i}}}{\sum_{i} w_{i}} \\
& \text { energy } \text { intensity }=\frac{\sum_{i} w_{i} E_{i / n_{i}}}{\sum_{i} w_{i}} / \frac{\sum_{i} w_{i} h_{i / p_{i}}}{\sum_{i} w_{i}}
\end{aligned}
$$

\section{Results}

We first comment on national average ${ }^{18}$ activity patterns, non-E expenditure intensities and energy intensities of all households in our extended database, highlighting the variability of time and intensities across activities. Then, to demonstrate the heterogeneity of activity patterns and intensities among households, we push our analysis further by disaggregating

\footnotetext{
${ }^{16}$ The household reference person counts one consumption unit (CU), additional individuals 14 or above 0.5 $\mathrm{CU}$ and additional individuals below $140.3 \mathrm{CU}$. We normalise energy consumptions and expenses on a per $\mathrm{CU}$ basis rather than on a per capita basis, to account for the economies of scale of households with more than one person.

${ }^{17}$ As their analytical formulations make clear, our intensities really are $€$ or $\mathrm{kWh}$ per consumption unit over hour of activity per person.

${ }^{18}$ Averages across households of our database weighted by national representativity weights.
} 
results for different income groups (deciles), household compositions (6 modes) and types of dwelling (houses vs. apartments).

\subsection{National average activity patterns, energy and non-E expendi- ture intensities}

The 13 activities in which we disaggregate the daily undertakings of French households are quite varied in terms of dedicated time, energy intensities and non-E expenditure intensities (Figure 2).

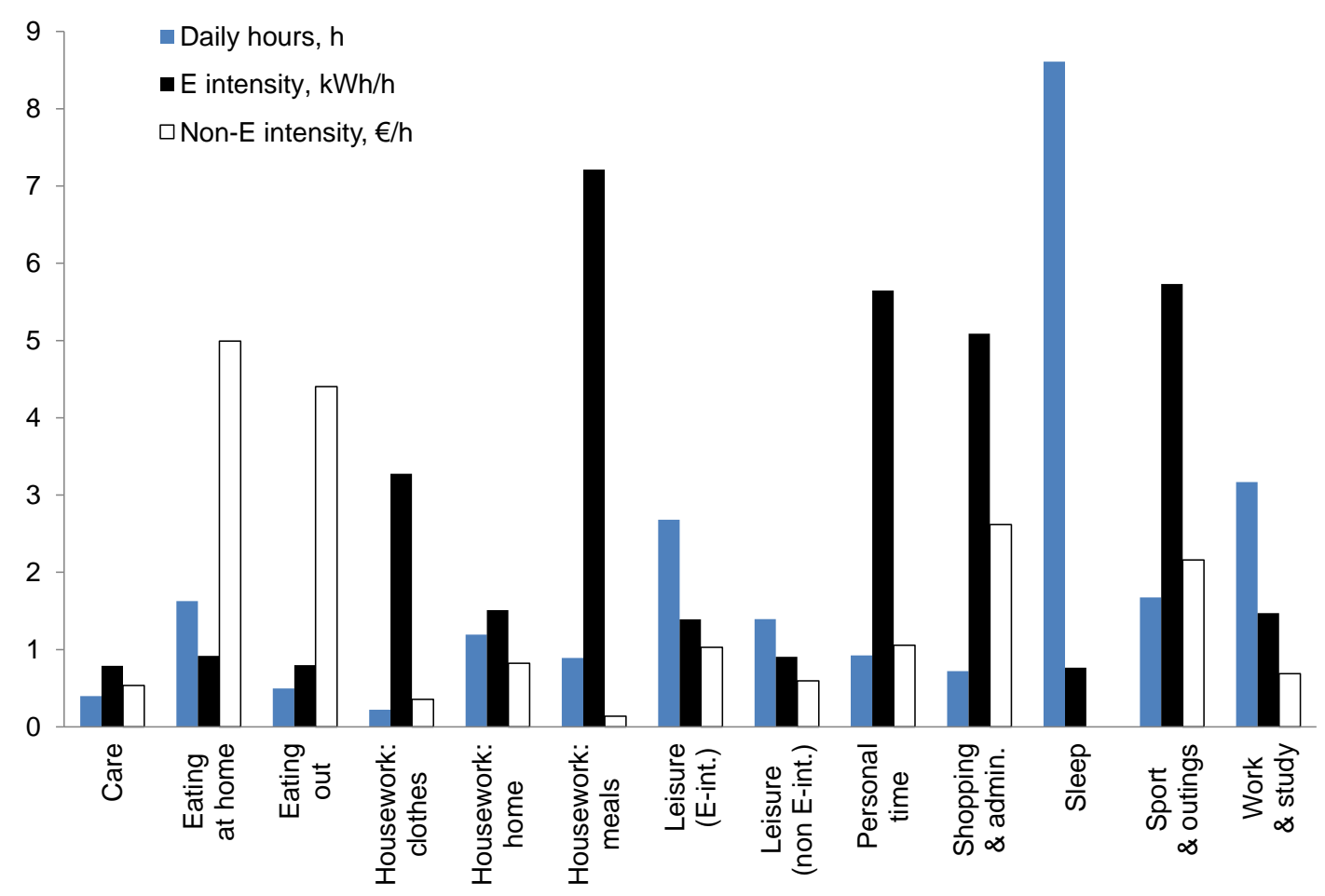

Figure 2: National average time use, energy intensity and non-E intensity of household activities.

After "Sleep" that takes up 8.6 hours per person per day, households spend the most of their time working or studying (3.2 h/pers./day), enjoying "Leisure (E-int.)" (2.7 h/pers./day), engaging in "Sport \& outings" (1.7 h/pers./day) or "Eating at home" (1.6 h/pers./day) (Fig. 2).

The highest (direct) energy intensity is that of "Housework: meals" (that is meal preparation and cleaning up), followed by "Sport \& outings", "Personal time" and "Shopping \& administration". The high intensities of "Housework: meals" and "Personal time" are caused by the additional, specific requirements of cooking and water-heating energy respectively, on top of base residential energy consumption and the energy consumption of dedicated appliances. The high direct energy intensity of meal cooking is consistent with the findings of micro-level studies, for example by Stankovic et al. [20] as regards electricity consumption. The other two activities that are very energy-intensive ("Sport \& outings" and "Shopping \& administration") are away-from-home activities: their high energy intensities are largely the result of the high share of travel time over total time (Table 3). Indeed, the energy intensity is calculated considering the total time use of away-from-home activities, but the only direct energy consumption 
associated with these activities is fuel for private vehicles. A larger share of travel time over total time, therefore, will be associated with a higher energy intensity. This, combined with the high modal share of private vehicles for these activities (respectively $67,6 \%$ for "Sport \& outings" and 89,5\% for "Shopping \& administration"), results in a high energy consumption over a relatively short total time, leading to a high energy intensity. Moreover, people tend to travel alone for these two activities. On the contrary, for an activity like "Eating out", people often travel together. If more than one household member go eating out together by car, average per capita fuel consumption for the household for this activity decreases, whereas average "Eating out" time per person stays the same. People often travel alone for work and study as well, but in that case, even if the modal share of private vehicles is high $(72,2 \%)$, the total time dedicated to the activity is much higher than for "Sport \& outings" and "Shopping \& administration", resulting in a lower intensity. Four of the five least energy-intensive activities are "Sleep", "Care", "Leisure (non energy-intensive)" and "Eating at home": the only energy attributed to these home activities is "base" heating/cooling and lighting (except for "Sleep"), whose expenses are attributed pro rata time use. The other activity marked by a low direct energy intensity is "Eating out", which is only allocated a share of fuel consumption for private vehicles. This low energy intensity is the result of low fuel consumption (which we already commented upon), compared to the relatively long hours dedicated to the activity.

Table 3: Share (\%) of travel time in total time for away-from-home activities

\begin{tabular}{lc}
\hline \hline Activity & $\begin{array}{c}\text { Share of travel time in } \\
\text { total time }\end{array}$ \\
\hline Eating out & 7.7 \\
Shopping \& administration & 41.3 \\
Sport \& outings & 33.3 \\
Work \& study & 10.8 \\
\hline
\end{tabular}

Regarding non-E expenditure intensities, the two eating activities turn out to be the most intensive (€4.99/hour for "Eating at home" and $€ 4.40 /$ hour for "Eating out" ${ }^{19}$ ), substantially above all other activities. This reflects the high budget share of sustenance expenses measured against the contained time budget devoted to eating. The higher expenditure intensity of "Eating at home" time in comparison to "Eating out" time might seem counter-intuitive, as restaurant prices should cover operating expenses as well as capital depreciation in addition to the cost of food. However, meals taken out last on average much longer than meals taken home - probably because of an additional average leisurely dimension. Right after eating activities, the high non-E expenditure intensities of "Shopping \& administration" and "Sport \& outings" time uses reflect the nature of the expenses allocated to these activities: beauty care and health services (for the "Shopping \& administration" time) and cultural and sports events (for the "Sport \& outings" time) have quite high prices compared to the relatively short time spent in them. At the opposite end of activities, the non-E expenditure intensity of "Sleep" is nil because we did not allocate any expense to that activity except the base heating or cooling energy expenditures that we convert into energy units. Apart from "Sleep", the least non-E intensive activities are "Housework: meals", "Housework: clothes" and "Care", which are characterized by little non-E consumption compared to the time spent in the activity. Accounting

\footnotetext{
${ }^{19}$ For the four away-from-home activities, non-E expenditure includes capital expenditure for the acquisition of cars, which we disaggregate across activities based on distances travelled. The share of this capital expenditure over total expenditure goes from $43 \%$ to $48 \%$ depending on the activity. If this expenditure were excluded from the analysis, non-E expenditure intensities for away-from-home activities would be correspondingly lower.
} 
for beds and bed linen, washing machines, ironing equipment, specific kitchen appliances, etc., would substantially increase their non-E intensities, although probably not to an extent that would upset the ranking of activities. ${ }^{20}$

Overall, the 3 characteristics revealed to each of our 13 activities shows remarkable variability. All 8 combinations of higher/lower dedicated time, higher/lower E-intensity and higher/lower non-E intensity are represented. This hints at large consequences of factoring in activity patterns and the relative substitutability of activities in energy consumption outlooks, all the more so if underlying energy efficiency trends (e.g. those on heating, lighting, transport or those specific to some appliances) differ.

\subsection{Sensitivity of activity pattern and intensities to income}

We now turn to results disaggregated by income per CU (hereafter simply "income") deciles with a view to analyse whether time uses and their energy and expenditure intensities present significant income elasticities in our database - a question of obvious interest to energy demand dynamics.

As households from different income deciles face a strictly identical time budget, it is interesting to look into the shifts from some activities to others as income increases. We observe some tendencies for such shifts (Figure 3): the time spent on "Work \& study" and "Eating out" increases with income while that spent on "Sleep", "Leisure (en.-intensive)", "Eating at home" and "Housework: meals" decreases - with some exceptions regarding the 1st income decile. This is the result of the presence in the first decile of a larger proportion of young single people, among which many students. The other activities exhibit less clear trends. The aggregation of travel times with the targeted away-from-home activities masks that travel times consistently increase with income (1st decile excluded again) from 1 hour per day and per person in the 2nd decile to 1.5 hours per day and per person in the 10th decile. The distribution across away-from-home activities also fluctuates, with travel time for "Work \& study" increasing with income at the expense of that for "Shopping \& administration".

Non-E intensities generally increase with income (Figure 4). The most non-E expenditure intensive activities on average, "Eating at home" and "Eating out", both show a quasi-exponential increase in non-E expenditure intensity with income. However, this intensity increase results from increasing non-E expenditure and slightly decreasing activity time for "Eating at home" vs. from expenditure increasing substantially faster than activity time (although the latter increases as well) for "Eating out". Meal preparation and consecutive cleaning up (combined in the activity "Housework: meals") exhibit a clear decrease in time use with income and an increase in energy use and non-E expenditure (even if absolute values for expenditure are low compared to other activities). This suggests a substitution of time with energy and other goods in the home production of meals as income grows, which could point for example at a higher reliance on prepared, frozen food requiring less preparation time but more direct energy.

We also observe that the non-E expenditure intensities of the highest income decile are particularly higher than those of the 9th decile for the "Eating at home", "Eating out" and "Sport \& outings" activities. In the case of "Eating out", this reflects a much increased non-E budget for a substantially higher time use, while for the two other activities it is only budget that is increased and time use is close to constant. Let us underline that parts of the almost

\footnotetext{
${ }^{20}$ For example, a $€ 500$ washing machine lasting 10 years to a 2 -CU household amounts to a $€ 2.08$ expense per CU and per month. Taking this expense into account would thus roughly double the "Housework: clothes" expense (cf. Table 3 in the Appendix) as well as the expenditure intensity of time spent on it. At ca. 0.7, it would remain significantly smaller than the 4 highest intensities previously commented upon.
} 


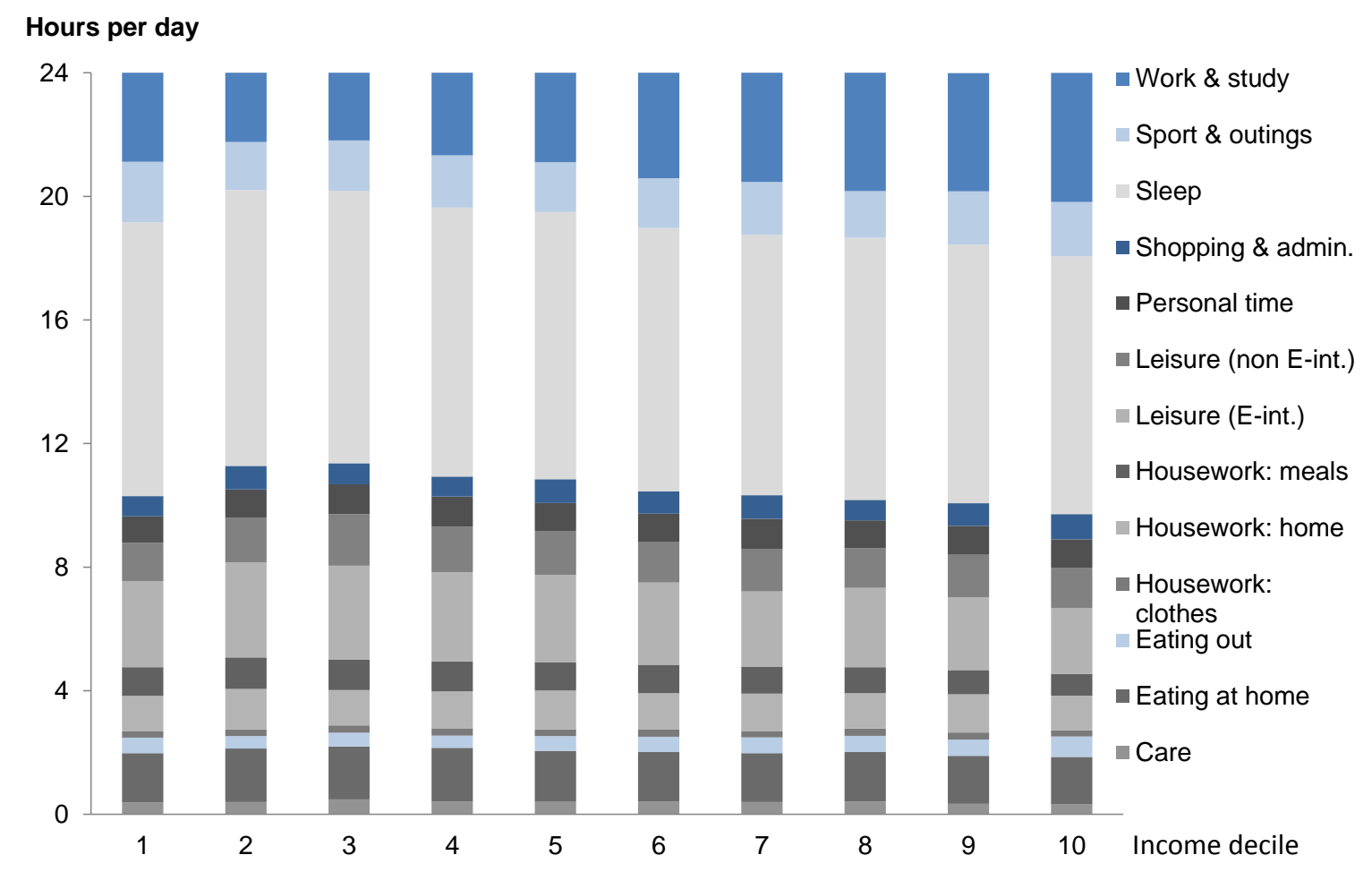

Figure 3: Average individual activity pattern by income decile

systematic increase in non-energy expenditure intensities could result from higher average prices of similar goods rather than from increased consumption volumes (more expensive restaurants, piece of garment, equipment, car, etc.). Girod and de Haan [30] indeed compare prices paid per functional unit of goods $\left(\mathrm{kg}, \mathrm{m}^{2}, \mathrm{pkm}\right)$ for a lower (below median) income group and a higher (above median) income group: they find that $62 \%$ of expenditures analysed at COICOP level 4 show significantly higher prices for the higher income group. For food categories, they estimate an average 17\% difference in price between the two income groups; based on BDF data, this difference is even higher when considering the 1st and 10th income deciles: we found that prices for food categories are, on average, $43 \%$ higher for the 10 th decile.

Energy intensities increase with income as well (Fig. 5), even though in a few cases the income decile having the highest energy intensity is not the 10th. For many activities, the highest energy intensities are more than twice the lowest ones. This is largely due to differences in "non-base" energy expenditure, i.e. specific energy consumption beyond heating/cooling and lighting energy. "Base" energy intensities are generally low compared to the total intensities. In Figure 5, they are revealed by the activities "Care", "Eating at home", "Leisure (non energyintensive)" and "Sleep", which could only be attributed base energy consumption. ${ }^{21}$

Household direct energy use depends on the activity pattern and on the energy intensity of each activity. To separate the effects of the two drivers, we estimate what the energy use of the average household belonging to the 10th income decile would be, if it had the same activity pattern as the average household of the 2 nd income decile, while retaining its

\footnotetext{
${ }^{21}$ Energy intensities of "Sleep" are slightly lower since lighting is excluded. For each household, the energy intensities of "Care", "Eating at home" and "Leisure (non E intensive)" are the same, as "base" energy expenditures were attributed to these activities proportionally to time use. There is a slight difference in average intensities of these activities for a given income group because we calculated average intensities as ratios of average energy use and time use, as outlined at the beginning of section 2.4.
} 


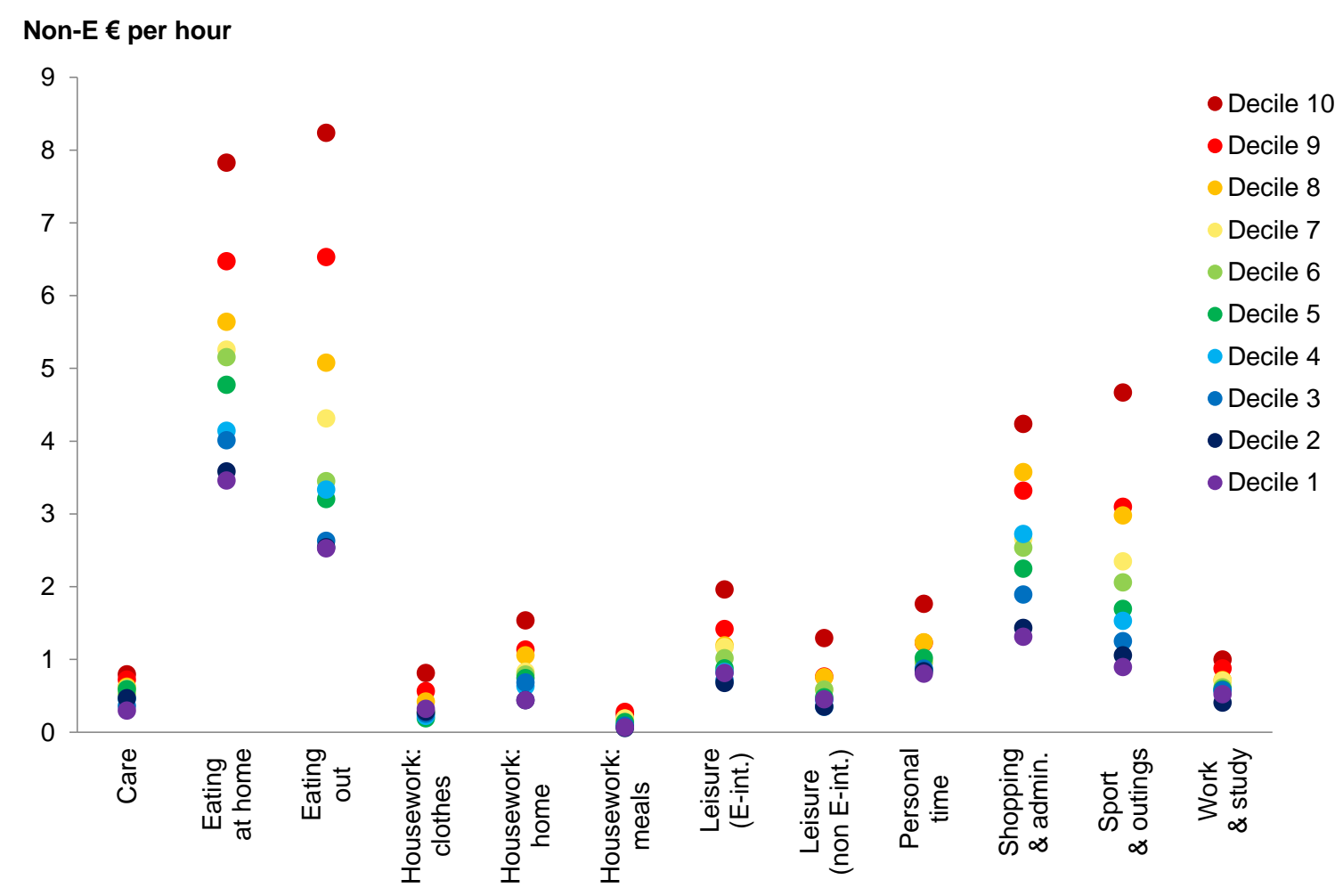

Figure 4: Average non-E expenditure intensities of household activities, by income decile

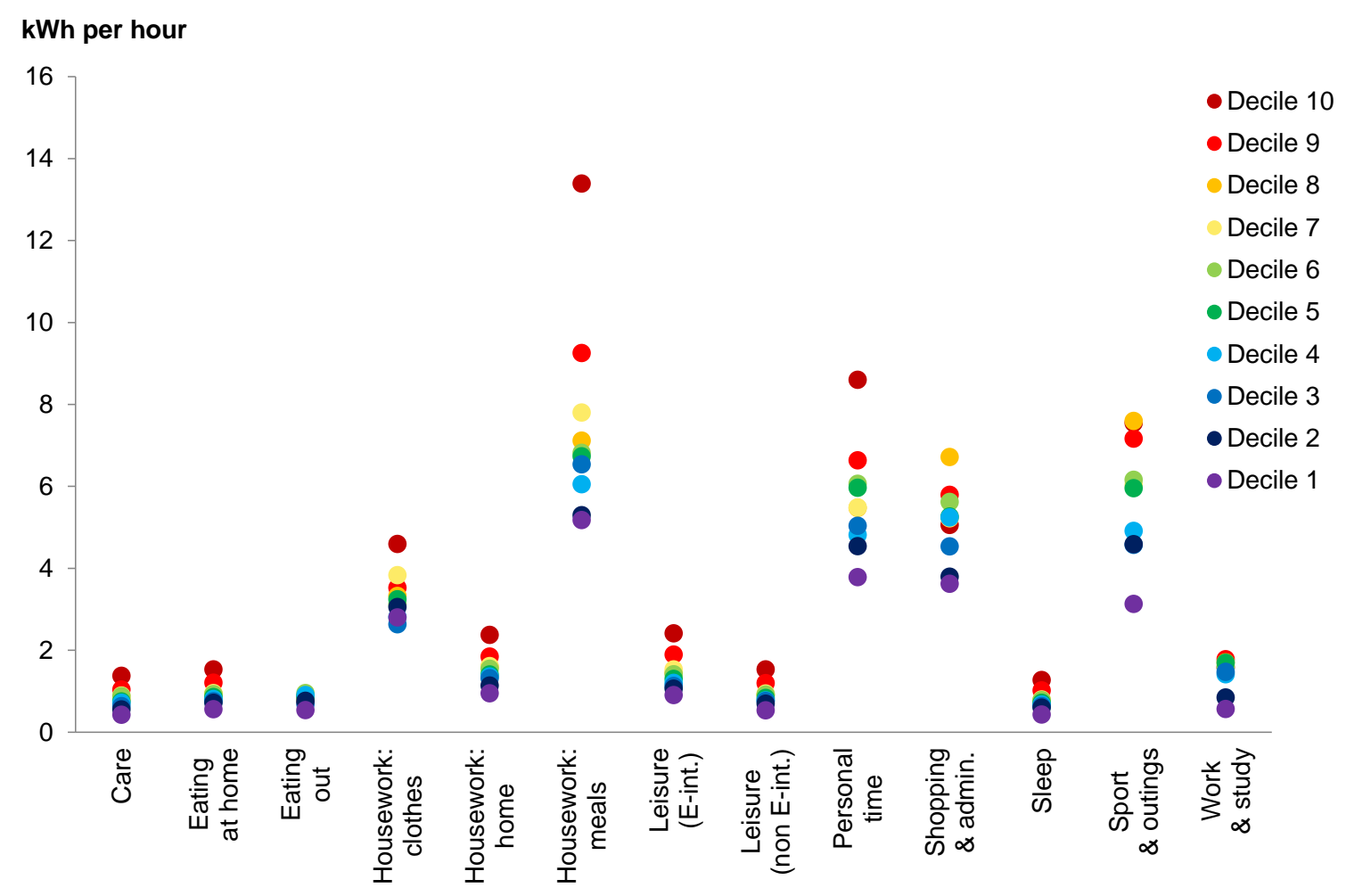

Figure 5: Average direct energy intensities of household activities, by income decile 
own energy intensities (we again set aside the 1st decile because of its specific demographics). Direct energy use per CU would be $4.7 \%$ higher as a result. Therefore, the activity pattern of richer households, who spend more time in "Work \& study" and "Eating out" and less time in "Sleep", "Leisure (energy intensive)" and "Eating at home" compared to households of the 2nd decile, causes a reduction in direct energy use. Average income per CU and energy uses of deciles allow estimating an income elasticity of direct energy use of 0.395. If all deciles had the activity pattern of the 2nd decile, the elasticity would be slightly higher, at $0.414 .^{22}$ This moderate impact of activity pattern shifts on income elasticities only prevails in a static framework considering fixed energy intensities of time uses of income groups. In a dynamic framework, e.g. in any energy demand outlook, the contrast of activity patterns across income groups warrants that any difference in the evolution of energy intensities of activities will induce markedly different variations of the energy consumptions of income subgroups.

\subsection{Sensitivity of activity pattern and intensities to household com- position}

To analyse whether also household demographics significantly impact activity patterns and intensities we consider 6 different household compositions: single person 65 or below, single person above 65 , couple without children with person of reference (PR) 65 or below, couple without children with PR above 65 , single parent, couple with children. However, household composition and income are highly correlated, as older households have generally higher income. To separate the effect of household composition from the effect of income, which we have already explored, we carry out our analysis of energy and expenditure intensities by household composition for each income quintile. For the sake of concision, we present the results for the third (median) quintile. The conclusions we draw would not change if we considered one of the other quintiles instead.

Household composition clearly influences the activity pattern, in expected ways (Fig. 6): time spent on "Work \& study" is extremely low for older households, who spend longer time on leisure activities, both energy intensive and non energy-intensive. The other activities also show marked differences in time use across household types. Couples without children with PR aged more than 65 spend the highest time eating at home and the lowest time eating out, whereas for single people under 65 the reverse is true. The household with the highest "Housework: meals" time are single people above 65, and couples with children are characterised by the lowest "Housework: meals" time per capita. "Housework: home" time for couple w/o children and PR above 65 is twice as high as the one for single parent households. "Care" time exhibits a great variability as well, being more than 4 times higher for couples with children than for single people 65 or below, for obvious reasons.

Household types also exhibit significant differences in the non-E and energy intensities of their activities (Figures 7 and 8). For the activity "Sport \& outings", couples without children, with PR 65 or below, show the highest non-E expenditure intensity, which is twice as high as the one of single people above 65 . The two types of leisure show large relative differences between the highest and lowest values as well. The non-E expenditure intensities of "Leisure (non E-int.)" and "Leisure (E-int.)" for couples with children are respectively three times and 2.3 times those of couples without children, PR above 65. For the activity "Eating at home", the most expenditure intensive household types are single persons below 65 and single

\footnotetext{
${ }^{22}$ Both elasticities are computed on the set of average income per consumption unit and average direct energy consumption per consumption unit for the 10 income deciles. The R2 of both estimations are notably high, at .990 for the former elasticity and 0.983 for the latter.
} 


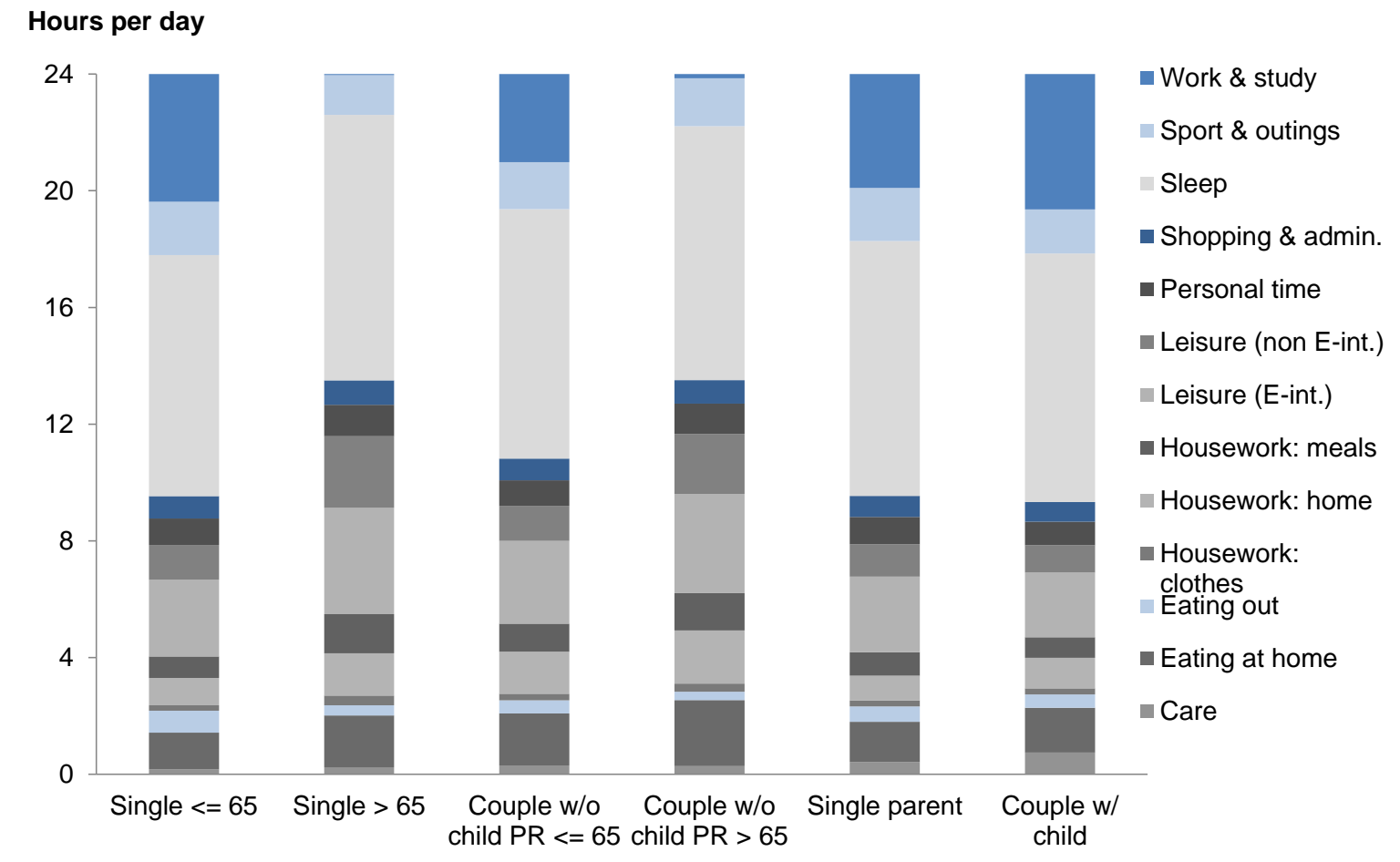

Figure 6: Average individual activity pattern by household composition, for the 3rd income quintile

parents, as these households spend significantly lower times eating at home compared to other household types, whereas the differences in food expenditure among household types are less marked. Not surprisingly, the two household types that include children are associated with the highest expenditure intensities of "Work \& study", because expenditure for this activity includes all educational expenditure - whereas professional expenditures are largely covered by employers.

Turning to energy, it is interesting to observe that some activities have similar energy intensities across household types, for example "Care", "Eating at home", "Leisure" (both kinds) and "Sleep" (the highest E-intensity is 1.1 to 1.7 times the lowest E-intensity). Other activities are characterized by a much larger variation across household types. For example, the energy intensity of "Eating out" for couples without children, PR 65 or below, is 6 times the energy intensity for couples without children, PR above 65. For "Housework: clothes", households with children have clearly higher energy intensities, partly explained by the energy consumption of washing machines and dryers being correlated with their dimensions and therefore with household size. Single parents show the highest energy intensity for the activity, which is 2.6 times the energy intensity for single people above 65 . These results specifically warrant paying attention to household composition trends (e.g. caused by ageing) in any long-term analysis of final energy consumption, confirming recent analysis by Huebner et al. [31, 32], who found that socio-demographic variables alone explained respectively $24 \%$ of the variability in domestic energy consumption (gas and electricity combined) and $21 \%$ of the variability in electricity consumption for English households. 


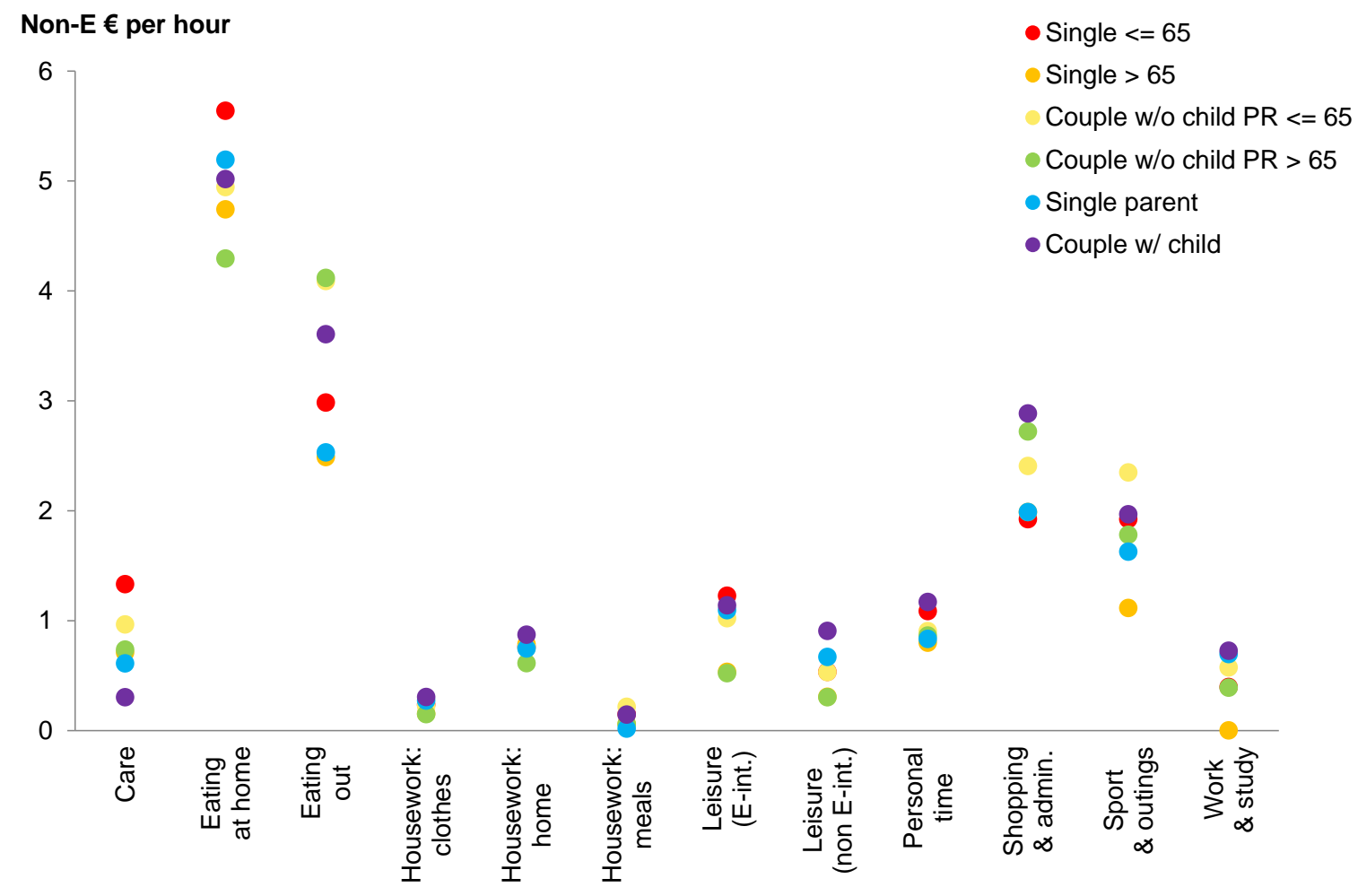

Figure 7: Average non-E expenditure intensities by household composition, for the 3rd income quintile

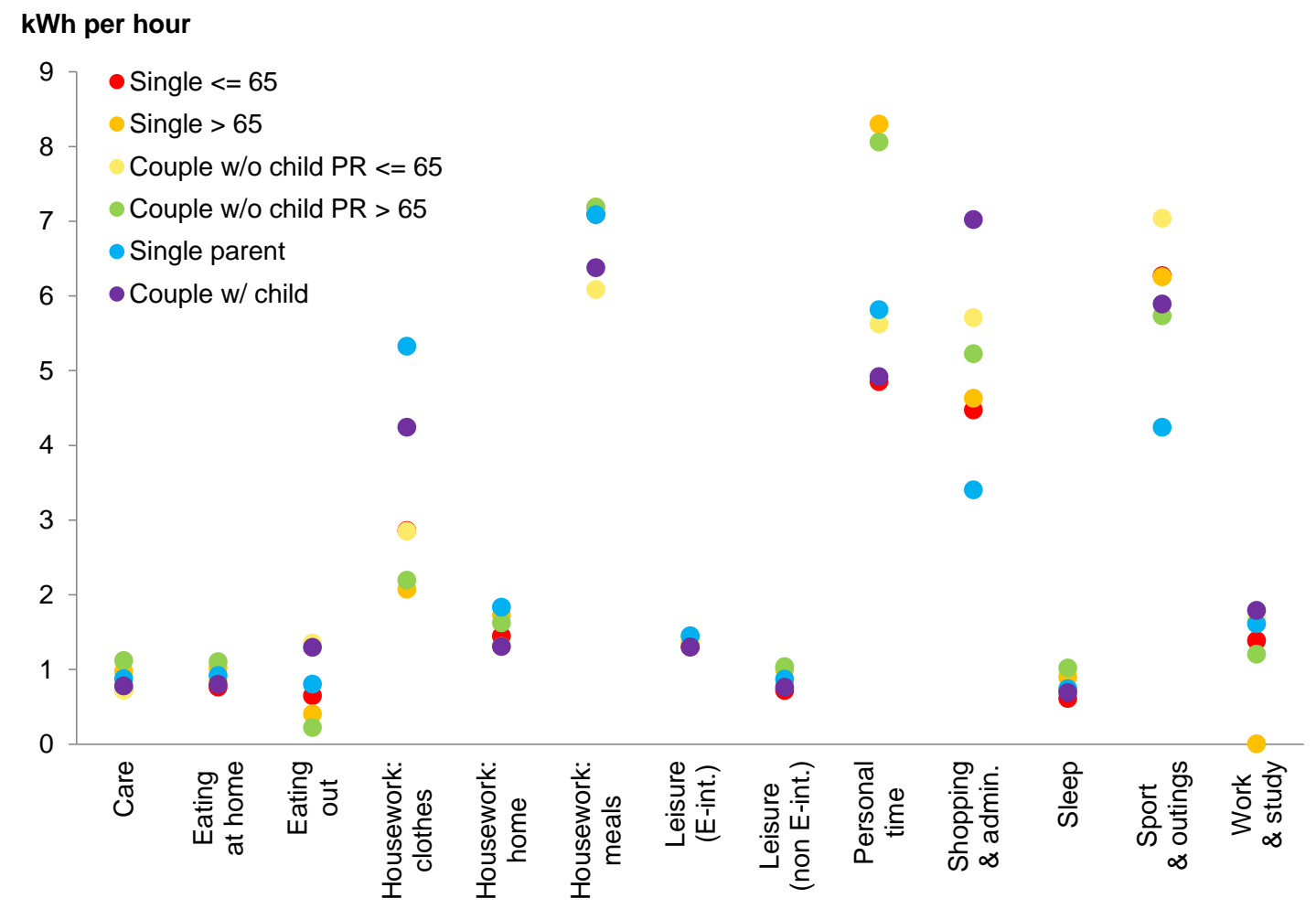

Figure 8: Average direct energy intensities by household composition, for the 3rd income quintile 


\subsection{Sensitivity of activity pattern and intensities to housing type}

Our third axis of analysis is the type of housing. We disaggregate our results between houses (including attached and detached housing) and apartments. Housing type acts as a proxy for a combination of other variables, such as dwelling surface or the type of residential area (central, suburbs, rural, etc.). Because housing type is also correlated to income, we again break down the analyses below into income groups. Considering only 2 housing types allows us to report the results concerning the bottom (Q1) and top (Q5) income quintiles in addition to the median one (Q3).

Starting again with activity patterns (Figure 9), we observe that the effect of housing type is narrower than it was for household composition. It is most evident for (total) housework time, which is $40 \%$ to $52 \%$ higher for households living in houses (depending on income quintile) than for households living in apartments. It is also noticeable concerning "Eating at home" (from $24 \%$ to $29 \%$ higher for households in houses) and, conversely, for "Eating out" (from $31 \%$ to $44 \%$ lower). However, the time dedicated to other activities shows less variability between housing types.

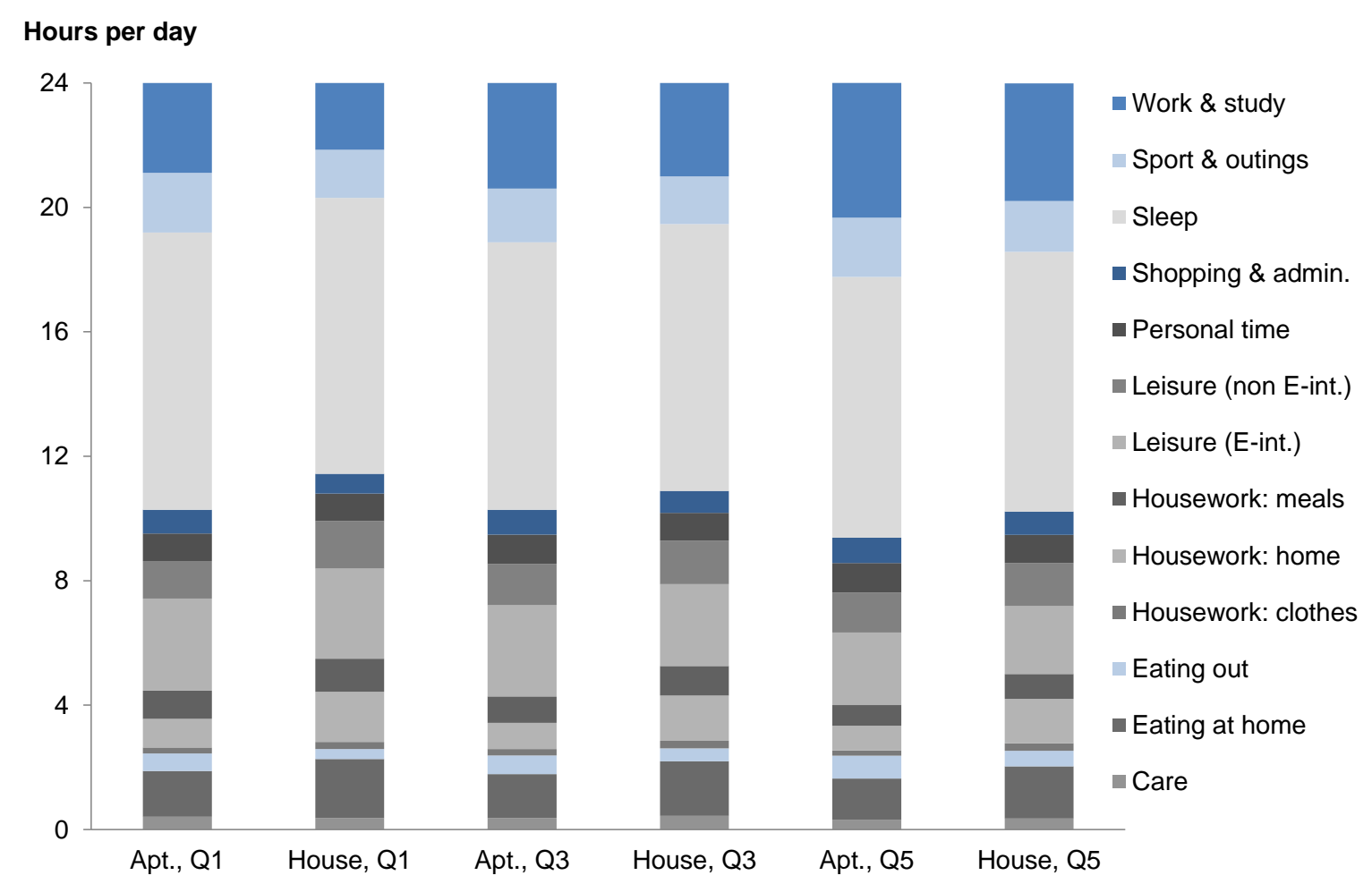

Figure 9: Average individual activity pattern by housing type, for 3 income quintiles

The impact of housing type on non-durable, non-E expenditure intensities is also less strong than that of income, although it is noticeably varied (Figure 10). "Care" has a markedly higher non-E intensity for households living in houses, particularly so for the first quintile $(+188 \%)$, which betrays the possession of pets (the only non-E expenditure specific to the activity). "Sport \& outings" and "Shopping \& admin." also exhibit quite higher non-E intensities for households living in houses, because houses are more frequently set in rural areas, which induce higher travel expenditures, in terms of car acquisition and maintenance and public transport fares. These higher expenditures impact as well on the non-E intensities of the two other awayfrom-home activities, "Eating out" and "Work \& study", but only moderately because they spread over longer activity times. One exception is "Work \& study" for the first quintile, which 
is $28 \%$ less non-E expenditure intensive for households in houses than it is for households in apartments. This could be because small farmers, who live in houses but do not require commuting, concentrate in this low-income group. Under similar budget constraints, higher pet and transport expenditures of households living in houses come at the expense of other activities, whose intensities are consequently below those computed for households living in apartments. The correction is fairly evenly spread across remaining activities, with one particular stress on "Housework: clothes", whose intensity is $28 \%$ (Q3) to $50 \%$ (Q5) lower. Lastly, "Housework: meals" stands out because it is more non-E intensive in houses for Q1 $(+55 \%)$ and Q5 $(+13 \%)$ but not for Q3 (-16\%).

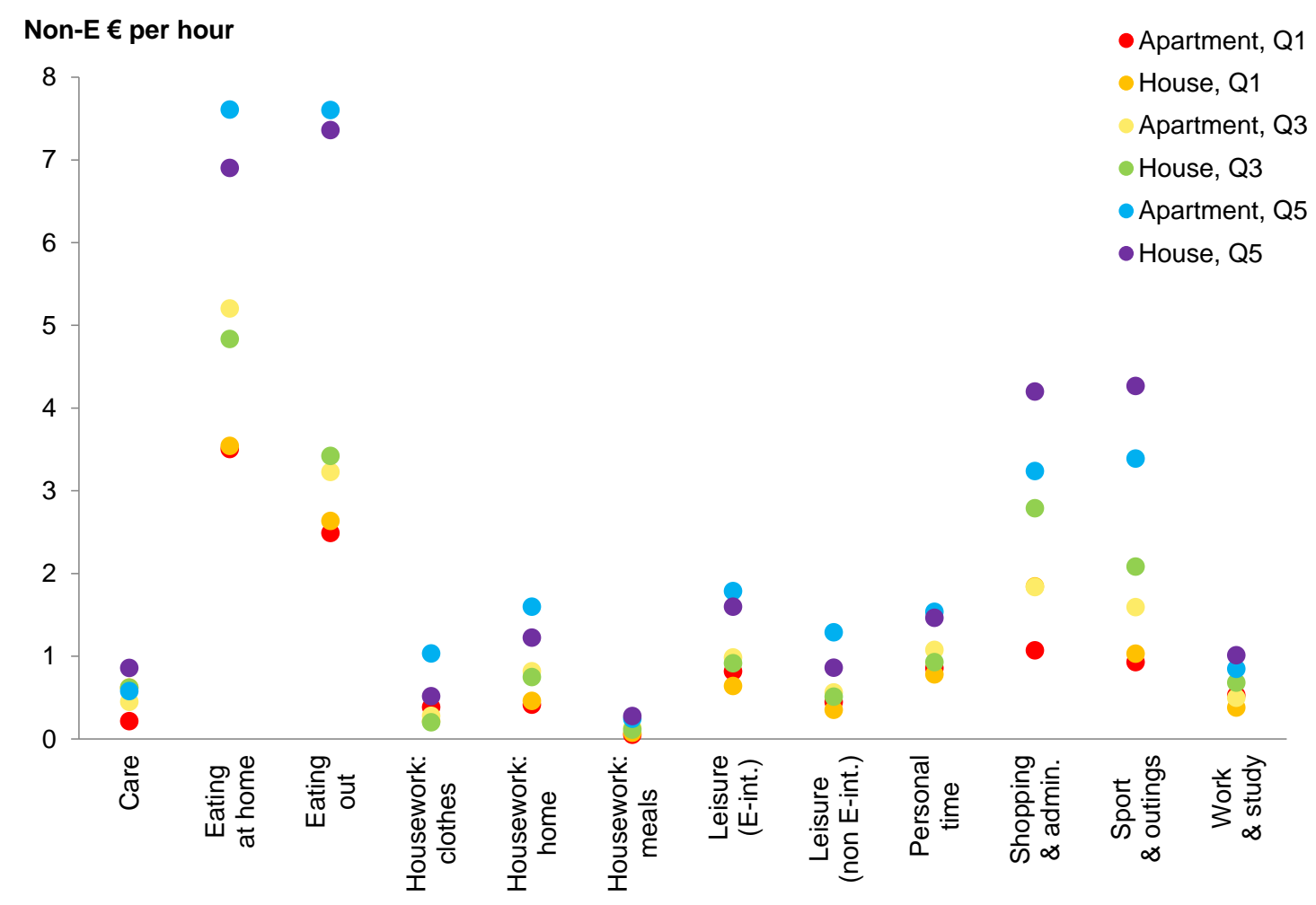

Figure 10: Average non-E expenditure intensities by housing type, for 3 income quintiles

Turning to direct energy use, our data analysis reveals a major influence of housing type on the energy intensities of activities (Figure 11), which again confirms the study of Huebner et al. [31] for England (with building variables explaining 39\% of the variability in domestic energy consumption), or that of Yun and Steemers [33] for the United States (as specifically regards cooling). For many activities and across quintiles, the energy intensity of households living in houses is more than double that of households living in apartments. For home activities this gap is caused by houses having larger average surfaces and higher thermal losses, because of the absence of other juxtaposed dwellings. This causes higher "base" energy consumption for heating/cooling and lighting. Moreover, the EDF R\&D electricity demand survey that we used for electricity expenditure disaggregation indicates that a larger available surface is generally associated with larger household sizes and thus larger appliances, which have higher electricity consumptions. This impact of housing type on appliance electricity consumption is particularly evident for "Housework: clothes" and "Personal time". In the case of "Personal time", though, a possible bias stems from expenditure for warm water being sometimes included in service charges paid by households living in apartments.

Away-from-home activities also exhibit contrasted energy intensities for the two housing 


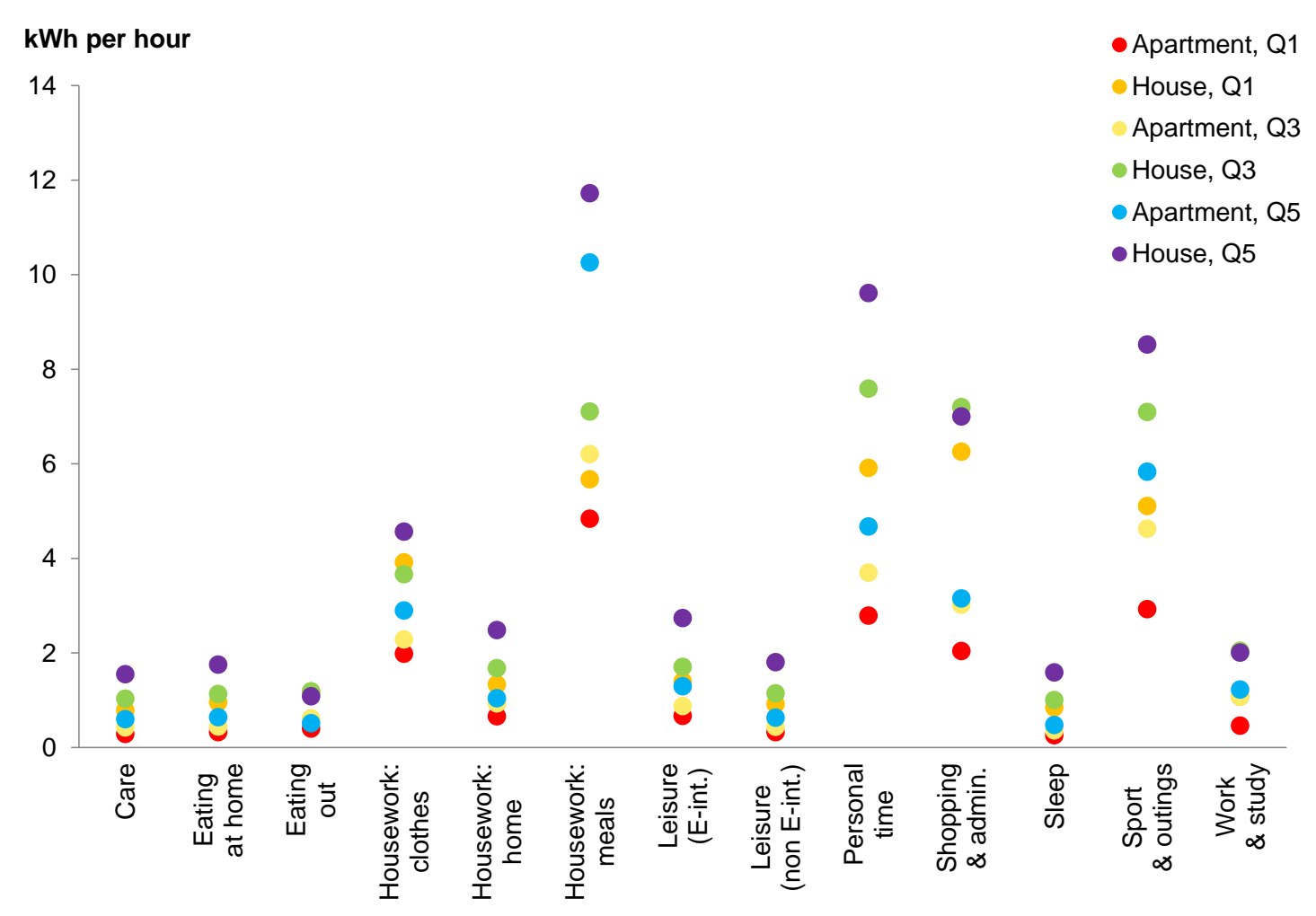

Figure 11: Average direct energy intensities by housing type, for 3 income quintiles

types, even though the only direct energy consumption associated with them is fuel for private cars. This is again because housing type acts as a proxy variable for urban density and thus the density of public transport provision: houses are more common in the suburbs or in rural areas, where it is more difficult to access public transport or to walk to work, school, shops or other services, resulting in a predominant use of the car. The French 2008 travel survey thus reports that households living in rural areas have a larger number of vehicles per household, for all income quintiles. Moreover, living in a house is associated with higher income, larger dwelling surface and household size and therefore it is also associated with the possession of bigger, hence less fuel-efficient cars: for all income quintiles, rural car owners have a larger share of medium and big cars (weight equal to, or higher than, $1000 \mathrm{~kg}$ ) than urban car owners. Among away-from-home activities, we observe the largest differences in energy intensities between the two types of dwelling for "Shopping \& administration". This is because travel represents a much larger share of the total time allocated to this activity compared to the other away-from-home activities, as we mentioned before.

\section{Conclusion and discussion}

From the analysis of our original extended database we draw two main conclusions. One first conclusion is on the significant variability of the average time, energy use and non-E expenditure dedicated to daily activities, without any apparent correlation between the 3 characteristics: activities with higher or lower average time uses can indifferently have higher or lower average direct energy intensities as well as higher or lower average non-E expenditure intensities. This has important bearing on energy consumption dynamics. The unescapable time constraint on daily activities means that any variation of one activity time, whether an increase or a decrease, will induce adjustments of other activity times. The variability that we have revealed implies 
that the aggregate impact on direct energy consumption of lifestyle changes will greatly depend upon the nature of this adjustment via the specific energy intensities of the mix of adjusted activity times. Besides, the variability of non-E expenditure intensities suggests that changes in activity patterns could also have an impact on indirect energy consumption (embodied energy could be calculated for the different products and services that correspond to each activity, although, as we mentioned in the results section, price differences among households should be taken into account to avoid bias). This is a generalisation of the time rebound effect argument developed by Jalas [14] for the use of some appliances, and a demonstration of its significance when considering a comprehensive set of daily activities and a complete distribution of direct energy consumptions.

Our second conclusion is on the influence of 3 household characteristics pertaining to the economic (income per CU), socio-demographic (household composition) and "socio-geographic" (type of housing, acting as proxy of social, demographic as well as technical variables) dimensions. We establish that income is a major determinant of activity patterns and (expectedly) of the energy and non-E expenditure intensities of activities, although the elasticity of energy consumption to income, at ca 0.4 (section 3.2), turns out to be only marginally impacted by activity pattern differences; that the composition of households largely determines their activity patterns as well as the energy and non-E expenditure intensities of some, but not all of these activities; that, somewhat conversely, the housing type of households strongly impacts all energy intensities of their time uses - by close to a factor 2 for many time uses and quite beyond that for some - but has a more limited impact on their activity patterns. We thus confirm that the energy consumption of households results from activity patterns and energy intensities of activities that show substantial variations across household subgroups. This implies that the specific dynamics of these subgroups should be explicitly considered when forecasting household energy consumption.

These two conclusions have particular bearing on economywide modelling applied to scenario analysis of household energy consumption. Most large scale energy-economy models build upon the microeconomic standard of utility maximisation under budget constraint. They consequently overlook any time constraint, at the risk of picturing budget allocations that are hardly compatible with any plausible average activity pattern. Large-scale models also often stick to the assumption of the "representative" household, whose consumption behaviour is aggregated over the entire population and calibrated on past observations. ${ }^{23}$ Aggregation forbids accounting for the behavioural specificities of household subgroups [35, 36, 37]. Any evolution of the relative weights of such subgroups in the total population outside the trends embodied in past observations will induce aggregate consumption shifts that will thus be overlooked. Beyond income issues, population ageing, typically, is an accelerating phenomenon in many developed countries that had better be treated explicitly by proper disaggregation of household groups. The increasing proportion of single-parent households could be another demographic trend with important energy intensity consequences. The balance of houses vs. apartments is one more open question, which should be addressed by sensitivity analysis and scenario variants. It could in fact be one major lever of policy intervention, considering its bearing on the energy intensities of activities. ${ }^{24}$

\footnotetext{
${ }^{23}$ Some models disaggregate households by income group (see e.g. [34]). This is an improvement over the representative household aggregation but our analysis reveals that other disaggregation keys should be considered as well.

${ }^{24}$ We postpone any substantiated discussion of the policy implications of our findings to further research where we can develop it on energy demand trajectories built upon them.
} 


\section{Acknowledgements}

The authors would like to thank two anonymous reviewers for their useful comments.

\section{A Appendix}

Table 1: List of the 94 explanatory variables used in the regressions for matching EDT and BDF surveys

\begin{tabular}{|c|c|c|c|}
\hline Variable name & Type & Description & Reference category \\
\hline Decile 2 & Categorical & Income per consumption unit, decile 2 & Decile 1 \\
\hline Decile 3 & Categorical & Income per consumption unit, decile 3 & Decile 1 \\
\hline Decile 4 & Categorical & Income per consumption unit, decile 4 & Decile 1 \\
\hline Decile 5 & Categorical & Income per consumption unit, decile 5 & Decile 1 \\
\hline Decile 6 & Categorical & Income per consumption unit, decile 6 & Decile 1 \\
\hline Decile 7 & Categorical & Income per consumption unit, decile 7 & Decile 1 \\
\hline Decile 8 & Categorical & Income per consumption unit, decile 8 & Decile 1 \\
\hline Decile 9 & Categorical & Income per consumption unit, decile 9 & Decile 1 \\
\hline Decile 10 & Categorical & Income per consumption unit, decile 10 & Decile 1 \\
\hline Age_PC1 & Continuous & Age 1st Principal Component Analysis (PCA) comp. & \\
\hline Age_PC2 & Continuous & Age 2nd PCA component & \\
\hline Age_PC3 & Continuous & Age 3rd PCA component & \\
\hline Age_PC4 & Continuous & Age 4th PCA component & \\
\hline Age_PC5 & Continuous & Age 5th PCA component & \\
\hline Sex $\bar{W}$ & Categorical & Sex: woman & Man \\
\hline Nationality 2 & Categorical & French (acquired) & French (at birth) \\
\hline Nationality 3 & Categorical & European Union & French (at birth) \\
\hline Nationality 5 & Categorical & Algeria, Morocco, Tunisia & French (at birth) \\
\hline Nationality 6 & Categorical & African countries except Algeria, Morocco, Tunisia & French (at birth) \\
\hline Nationality 7 & Categorical & Other or stateless & French (at birth) \\
\hline Type of day 2 & Categorical & Half-day & Regular work day \\
\hline Type of day 3 & Categorical & Holiday & Regular work day \\
\hline Type of day 4 & Categorical & Sick leave & Regular work day \\
\hline Type of day 5 & Categorical & Other & Regular work day \\
\hline $\mathrm{SPC} \_\mathrm{PC} 1$ & Continuous & Socio-Economic Classification, 1st PCA comp. & \\
\hline $\mathrm{SPC} \_\mathrm{PC} 2$ & Continuous & SEC, 2nd PCA component & \\
\hline $\mathrm{SPC} \_\mathrm{PC} 3$ & Continuous & SEC, 3rd PCA component & \\
\hline $\mathrm{SPC} \_\mathrm{PC} 4$ & Continuous & SEC, 4th PCA component & \\
\hline $\mathrm{SPC} \_\mathrm{PC} 5$ & Continuous & SEC, 5th PCA component & \\
\hline SPC_PC6 & Continuous & SEC, 6th PCA component & \\
\hline $\mathrm{SPC} \_\mathrm{PC} 7$ & Continuous & SEC, 7th PCA component & \\
\hline $\mathrm{SPC} \_\mathrm{PC} 8$ & Continuous & SEC, 8th PCA component & \\
\hline SPC_PC9 & Continuous & SEC, 9th PCA component & \\
\hline SPC_PC10 & Continuous & SEC, 10th PCA component & \\
\hline SPC_PC11 & Continuous & SEC, 11th PCA component & \\
\hline SPC_PC12 & Continuous & SEC, 12th PCA component & \\
\hline Household composition 2 & Categorical & Single pers. below 65 & Child \\
\hline Household composition 3 & Categorical & Couple without children (HR below 65 ) & Child \\
\hline Household composition 4 & Categorical & Single parent & Child \\
\hline Household composition 5 & Categorical & Couple with children & Child \\
\hline Household composition 6 & Categorical & Couple without children (HR above 65 ) & Child \\
\hline Household composition 7 & Categorical & Single pers. above 65 & Child \\
\hline Size of urban area 1 & Categorical & Less than 5000 inhabitants & Rural \\
\hline Size of urban area 2 & Categorical & 5,000 - 9,999 inhabitants & Rural \\
\hline Size of urban area 3 & Categorical & 10,000 - 19,999 inhabitants & Rural \\
\hline Size of urban area 4 & Categorical & 20,000 - 49,999 inhabitants & Rural \\
\hline Size of urban area 5 & Categorical & 50,000 - 99,999 inhabitants & Rural \\
\hline Size of urban area 6 & Categorical & $100,000-199,999$ inhabitants & Rural \\
\hline Size of urban area 7 & Categorical & $200,000-1,999,999$ inhabitants & Rural \\
\hline Size of urban area 8 & Categorical & Paris urban area & Rural \\
\hline Type of urban area 112 & Categorical & Suburbs of big cities & Big cities $(>10,000$ jobs $)$ \\
\hline Type of urban area 120 & Categorical & Satellite towns of big cities & Big cities $(>10,000$ jobs $)$ \\
\hline Type of urban area 211 & Categorical & Medium-sized cities $(5,000-10,000$ jobs $)$ & Big cities ( $>10,000$ jobs $)$ \\
\hline Type of urban area 212 & Categorical & Suburbs of medium-sized cities & Big cities ( $>10,000$ jobs $)$ \\
\hline Type of urban area 221 & Categorical & Small towns (less than 500 jobs) & Big cities ( $>10,000$ jobs $)$ \\
\hline Type of urban area 222 & Categorical & Suburbs of small towns & Big cities ( $>10,000$ jobs $)$ \\
\hline Type of urban area 300 & Categorical & Other satellite towns & Big cities $(>10,000$ jobs $)$ \\
\hline
\end{tabular}


Table 1 continued

\begin{tabular}{|c|c|c|c|}
\hline Variable name & Type & Description & Reference category \\
\hline Type of urban area 400 & Categorical & Isolated boroughs & Big cities ( $>10,000$ jobs $)$ \\
\hline Geographical area 1 & Categorical & Paris region & Overseas dept. \\
\hline Geographical area 2 & Categorical & Paris influence area & Overseas dept. \\
\hline Geographical area 3 & Categorical & North & Overseas dept. \\
\hline Geographical area 4 & Categorical & East & Overseas dept. \\
\hline Geographical area 5 & Categorical & West & Overseas dept. \\
\hline Geographical area 7 & Categorical & South-west & Overseas dept. \\
\hline Geographical area 8 & Categorical & Centre-east & Overseas dept. \\
\hline Geographical area 9 & Categorical & Mediterranean & Overseas dept. \\
\hline Ownership status 2 & Categorical & Owner & Owner on mortgage \\
\hline Ownership status 3 & Categorical & Usufructuary & Owner on mortgage \\
\hline Ownership status 4 & Categorical & Tenant or subtenant & Owner on mortgage \\
\hline Ownership status 5 & Categorical & Free accommodation & Owner on mortgage \\
\hline Surface & Continuous & Surface of dwelling, $m^{2}$ & \\
\hline Neighbourhood type 2 & Categorical & Houses, urban & Houses, rural \\
\hline Neighbourhood type 3 & Categorical & Blocks of flats in town & Houses, rural \\
\hline Neighbourhood type 4 & Categorical & Housing projects & Houses, rural \\
\hline Neighbourhood type 5 & Categorical & Mixed & Houses, rural \\
\hline Dwelling type 2 & Categorical & Terraced house & Detached house \\
\hline Dwelling type 3 & Categorical & Flat in a two-flat building & Detached house \\
\hline Dwelling type 4 & Categorical & Flat in a 3 - to 9 -flat building & Detached house \\
\hline Dwelling type 5 & Categorical & Flat in a building with 10 or more flats & Detached house \\
\hline TV set & Dummy & Possession of a TV set & \\
\hline Computer & Dummy & Possession of a computer & \\
\hline Internet & Dummy & Availability of Internet connection & \\
\hline Telephone & Dummy & Possession of a landline telephone & \\
\hline Mobile telephone & Dummy & Possession of a mobile phone & \\
\hline Microwave & Dummy & Possession of a micro-wave & \\
\hline Dishwasher & Dummy & Possession of a dishwasher & \\
\hline Washing machine & Dummy & Possession of a washing machine & \\
\hline Motorbike or scooter & Dummy & Possession of a motorbike or scooter & \\
\hline Car & Dummy & Possession of a car & \\
\hline Garden & Dummy & Presence of a garden & \\
\hline Cat & Dummy & Presence of cats & \\
\hline Dog & Dummy & Presence of dogs & \\
\hline Other animals & Dummy & Presence of other animals & \\
\hline Domestic worker & Dummy & Resort to paid domestic work services & \\
\hline
\end{tabular}

Table 2: Summary of regression results

\begin{tabular}{lcccc}
\hline \hline Activity & $D F$ & $R^{2}$ & $F-$ stat. & $p$ \\
\hline Care & 23257 & 0.2002 & 61.93 & $<2.2 \times 10^{-16}$ \\
Eating at home & 23257 & 0.1671 & 49.64 & $<2.2 \times 10^{-16}$ \\
Eating out & 23257 & 0.0688 & 18.28 & $<2.2 \times 10^{-16}$ \\
Housework: clothes & 23257 & 0.1095 & 30.41 & $<2.2 \times 10^{-16}$ \\
Housework: home & 23257 & 0.1660 & 49.25 & $<2.2 \times 10^{-16}$ \\
Housework: meals & 23257 & 0.2847 & 98.50 & $<2.2 \times 10^{-16}$ \\
Leisure (energy-int.) & 23257 & 0.1637 & 48.43 & $<2.2 \times 10^{-16}$ \\
Leisure (non energy-int.) & 23257 & 0.1603 & 47.23 & $<2.2 \times 10^{-16}$ \\
Personal time & 23257 & 0.0602 & 15.84 & $<2.2 \times 10^{-16}$ \\
Shopping \& admin. & 23257 & 0.0772 & 20.69 & $<2.2 \times 10^{-16}$ \\
Sleep & 23257 & 0.1766 & 53.08 & $<2.2 \times 10^{-16}$ \\
Sport \& outings & 23257 & 0.1262 & 35.75 & $<2.2 \times 10^{-16}$ \\
Work \& study & 23257 & 0.7427 & 713.99 & $<2.2 \times 10^{-16}$ \\
\hline
\end{tabular}


Table 3: National averages of non-E expense, E consumption, time use and intensities of household activities

\begin{tabular}{lccccc}
\hline \hline Activity & $\begin{array}{c}\text { non-E } \\
\text { Exp. } \\
(€ / \text { day } / \\
\text { CU) }\end{array}$ & $\begin{array}{c}\text { Energy } \\
(\mathrm{kWh} / \text { day } / \\
\text { CU })\end{array}$ & $\begin{array}{c}\text { Time } \\
(\text { h/day/ } \\
\text { pers. })\end{array}$ & $\begin{array}{c}\text { non-E } \\
\text { exp. } \\
\text { intensity } \\
(€ / \mathrm{h})\end{array}$ & $\begin{array}{c}\text { Energy } \\
\text { intensity } \\
(\mathrm{kWh} / \mathrm{h})\end{array}$ \\
\hline Care & 0.21 & 0.31 & 0.40 & 0.54 & 0.79 \\
Eating at home & 8.13 & 1.50 & 1.63 & 4.99 & 0.92 \\
Eating out & 2.18 & 0.40 & 0.50 & 4.40 & 0.80 \\
Housework: clothes & 0.08 & 0.73 & 0.22 & 0.36 & 3.28 \\
Housework: home & 0.98 & 1.80 & 1.19 & 0.82 & 1.51 \\
Housework: meals & 0.12 & 6.43 & 0.89 & 0.14 & 7.21 \\
Leisure (energy-int.) & 2.75 & 3.73 & 2.68 & 1.03 & 1.39 \\
Leisure (non energy-int.) & 0.83 & 1.26 & 1.39 & 0.59 & 0.91 \\
Personal time & 0.98 & 5.21 & 0.92 & 1.06 & 5.65 \\
Shopping and admin. & 1.89 & 3.67 & 0.72 & 2.62 & 5.09 \\
Sleep & 0.00 & 6.60 & 8.61 & 0.00 & 0.77 \\
Sport and outings & 3.62 & 9.60 & 1.68 & 2.16 & 5.73 \\
Work and study & 2.18 & 4.66 & 3.17 & 0.69 & 1.47 \\
\hline Average across activities & 1.84 & 3.53 & 1.85 & 1.49 & 2.73 \\
\hline
\end{tabular}




\section{References}

[1] S. Bin and H. Dowlatabadi. Consumer lifestyle approach to US energy use and the related $\mathrm{CO}_{2}$ emissions. Energy Policy, 33(2):197-208, 2005. ISSN 0301-4215. doi:10.1016/S03014215(03)00210-6.

[2] Y.-M. Wei, L.-C. Liu, Y. Fan, and G. Wu. The impact of lifestyle on energy use and $\mathrm{CO}_{2}$ emission: An empirical analysis of China's residents. Energy Policy, 35(1):247-257, 2007. ISSN 0301-4215. doi:10.1016/j.enpol.2005.11.020.

[3] R. Duarte, A. Mainar, and J. Sánchez-Chóliz. The role of consumption patterns, demand and technological factors on the recent evolution of $\mathrm{CO}_{2}$ emissions in a group of advanced economies. Ecological Economics, 96:1-13, 2013. doi:10.1016/j.ecolecon.2013.09.007.

[4] W. Biesiot and K. J. Noorman. Energy requirements of household consumption: a case study of The Netherlands. Ecological Economics, 28:367-383, 1999. doi:10.1016/S09218009(98)00113-X.

[5] T. Jackson. Prosperity Without Growth: Economics for a Finite Planet. Earthscan, 2009.

[6] P. Moriarty and D. Honnery. A human needs approach to reducing atmospheric carbon. Energy Policy, 38:695-700, 2010. doi:10.1016/j.enpol.2009.10.043.

[7] L. Lutzenhiser. Social and behavioral aspects of energy use. Annual Review of Energy and the Environment, 18:247-289, 1993. doi:10.1146/annurev.eg.18.110193.001335.

[8] T. Jackson. Motivating sustainable consumption. a review of evidence on consumer behaviour and behavioural change. Technical report, University of Surrey, 2005. URL http://sustainablelifestyles.ac.uk/sites/default/files/motivating_sc_final.pdf.

[9] T. F. Sanquist, H. Orr, B. Shui, and A. C. Bittner. Lifestyle factors in U.S. residential electricity consumption. Energy Policy, 42:354-364, 2012. doi:10.1016/j.enpol.2011.11.092.

[10] G. S. Becker. A theory of the allocation of time. The Economic Journal, 75(299):493-517, 1965.

[11] R. Gronau and D. S. Hamermesh. Time vs. goods: The value of measuring household production technologies. Review of Income and Wealth, 52(1):1-16, 2006. doi:10.1111/j.14754991.2006.00173.x.

[12] D. S. Hamermesh. Time to eat: household production under increasing income inequality. American Journal of Agricultural Economics, 89(4):852-863, 2007. doi:10.1111/j.14678276.2007.01012.x.

[13] L. Schipper, S. Bartlett, D. Hawk, and E. Vine. Linking life-styles and energy use: a matter of time? Annual review of energy, 14(1):273-320, 1989. doi:10.1146/annurev.eg.14.110189.001421.

[14] M. Jalas. A time use perspective on the materials intensity of consumption. Ecological Economics, 41(1):109-123, 2002. doi:10.1016/S0921-8009(02)00018-6.

[15] V. Brenčič and D. Young. Time-saving innovations, time allocation, and energy use: Evidence from Canadian households. Ecological Economics, 68:2859-2867, 2009. doi:10.1016/j.ecolecon.2009.06.005. 
[16] M. Jalas. The everyday life context of increasing energy demands: Time use survey data in a decomposition analysis. Journal of Industrial Ecology, 9(1-2):129-145, 2005. doi:10.1162/1088198054084644.

[17] M. Jalas and J. K. Juntunen. Energy intensive lifestyles: Time use, the activity patterns of consumers, and related energy demands in Finland. Ecological Economics, 113:51-59, 2015. doi:10.1016/j.ecolecon.2015.02.016.

[18] A. Druckman, I. Buck, B. Hayward, and T. Jackson. Time, gender and carbon: A study of the carbon implications of British adults' use of time. Ecological Economics, 84:153-163, 2012. doi:10.1016/j.ecolecon.2012.09.008.

[19] K. Ellegøard and J. Palm. Visualizing energy consumption activities as a tool for making everyday life more sustainable. Applied Energy, 88(5):1920-1926, 2011. ISSN 0306-2619. doi:http://dx.doi.org/10.1016/j.apenergy.2010.11.019.

[20] L. Stankovic, V. Stankovic, J. Liao, and C. Wilson. Measuring the energy intensity of domestic activities from smart meter data. Applied Energy, 183:1565-1580, 2016. doi:10.1016/j.apenergy.2016.09.087.

[21] INSEE. Emploi du temps, (EDT) 2009-2010, 2010. URL https://www.cmh.ens.fr/greco/ enquetes/XML/lil.php?lil=lil-0695.

[22] INSEE. Budget des familles (BDF) 2011, 2011. URL https://www.cmh.ens.fr/greco/ enquetes/XML/lil.php?lil=lil-0831.

[23] S. P. Jenkins and N. C. O'Leary. Household income plus household production: the distribution of extended income in the U.K. Review of Income and Wealth, 42(4), 1996. doi:10.1111/j.1475-4991.1996.tb00191.x.

[24] F. Gardes. Full price elasticities and the value of time: A tribute to the Beckerian model of the allocation of time. w.p. CES, Paris School of Economics, University Paris I PanthéonSorbonne, 2014.

[25] INSEE. Enquête logement 2006, 2006. URL http://cmh.ens.fr/greco/enquetes/XML/lil. php?lil=lil-0410.

[26] MEEM. Enquête nationale transports et déplacements (ENTD) 2008, 2008. URL http://www.statistiques.developpement-durable.gouv.fr/sources-methodes/ enquete-nomenclature/1543/139/enquete-nationale-transports-deplacements-entd-2008. html.

[27] MEEM. Enquête Performance de l'Habitat, Équipements, Besoins et Usages de l'énergie (Phébus), 2013. URL http://www.statistiques. developpement-durable.gouv.fr/sources-methodes/enquete-nomenclature/1541/0/ enquete-performance-lhabitat-equipements-besoins-usages.html.

[28] MEEM. Base de donées Pégase (Pétrole, Électricité, Gaz et Autres Statistiques de l'Énergie). URL http://www.statistiques.developpement-durable.gouv.fr/donnees-ligne/ r/pegase.html. 
[29] SOeS. Les comptes des transports en 2010, tome 1. Technical report, Commissariat Général au Développement durable, 2011. URL http://www.statistiques.developpement-durable. gouv.fr/publications/p/1811/873/comptes-transports-2010.html.

[30] B. Girod and P. de Haan. More or better? a model for changes in housheold greenhouse gas emissions due to higher income. Journal of industrial ecology, 14(1):31-49, 2010. doi:10.1111/j.1530-9290.2009.00202.x.

[31] G. M. Huebner, I. Hamilton, Z. Chalabi, D. Shipworth, and T. Oreszczyn. Explaining domestic energy consumption - the comparative contribution of building factors, socio-demographics, behaviours and attitudes. Applied Energy, 159:589-600, 2015. doi:10.1016/j.apenergy.2015.09.028.

[32] G. Huebner, D. Shipworth, I. Hamilton, Z. Chalabi, and T. Oreszczyn. Understanding electricity consumption: A comparative contribution of building factors, sociodemographics, appliances, behaviours and attitudes. Applied Energy, 177:692-702, 2016. doi:10.1016/j.apenergy.2016.04.075.

[33] G. Y. Yun and K. Steemers. Behavioural, physical and socio-economic factors in household cooling energy consumption. Applied Energy, 88:2191-2200, 2011. doi:10.1016/j.apenergy.2011.01.010.

[34] R. Duarte, K. Feng, K. Hubacek, J. Sánchez-Chóliz, C. Sarasa, and L. Sun. Modeling the carbon consequences of pro-environmental consumer behavior. Applied Energy, 184: 1207-1216, 2016. doi:10.1016/j.apenergy.2015.09.101.

[35] M. Jaccard and M. Dennis. Estimating home energy decision parameters for a hybrid energy-economy policy model. Environmental Modeling and Assessment, 11:91-100, 2006. doi:10.1007/s10666-005-9036-0.

[36] G. Baiocchi, J. Minx, and K. Hubacek. The impact of social factors and consumer behavior on carbon dioxide emissions in the United Kingdom. Journal of Industrial Ecology, 14(1): 50-72, 2010. doi:10.1111/j.1530-9290.2009.00216.x.

[37] J.-M. Cayla and N. Maïzi. Integrating household behavior and heterogeneity into the TIMES-Households model. Applied Energy, 139:56-67, 2015. doi:10.1016/j.apenergy.2014.11.015. 